\title{
Recent Research Progresses in 2D Nanomaterial-based Photodetectors
}

\author{
Hye Yeon Jang*, Jae Hyeon Nam*, and Byungjin Cho ${ }^{\dagger}$
}

Department of Advanced Material Engineering, Chungbuk National University, Chungbuk 28644, Republic of Korea

\section{D 나노소재기반 광 센서 소자의 최근 연구 동향}

장혜연*, 남재현, 조병진 ${ }^{\dagger}$

충북대학교 신소재공학과

(Received February 19, 2019; Accepted March 5, 2019)

\begin{abstract}
Abstacts
Atomically thin two-dimensional (2D) nanomaterials, including transition metal dichalcogenides (TMDs), graphene, boron nitride, and black phosphorus, have opened up new opportunities for the next generation optoelectronics owing to their unique properties such as high absorbance coefficient, high carrier mobility, tunable band gap, strong light-matter interaction, and flexibility. In this review, photodetectors based on 2D nanomaterials are classified with respect to critical element technology (e.g., active channel, contact, interface, and passivation). We discuss key ideas for improving the performance of the $2 \mathrm{D}$ photodetectors. In addition, figure-of-merits (responsivity, detectivity, response speed, and wavelength spectrum range) are compared to evaluate the performance of diverse $2 \mathrm{D}$ photodetectors. In order to achieve highly reliable $2 \mathrm{D}$ photodetectors, in-depth studies on material synthesis, device structure, and integration process are still essential. We hope that this review article is able to render the inspiration for the breakthrough of the २D photodetector research field.
\end{abstract}

Keywords: 2D photodetector, heterostructure, contact, interface, passivation

\section{1. 서론}

빛을 전기 신호 형태로 변환하는 기술은 광통신, 차량
용 비전, 의료 영상, 거리 감지 등과 같은 다양한 광학 장 치에 주로 사용되어 왔으며 응용 및 확장성이 뛰어나 관 련 연구가 활발하게 진행되어 왔다. 특히, 광 검출 기술

*공동 제1저자 $\left({ }^{*} \mathrm{Co}-\right.$ first author) 


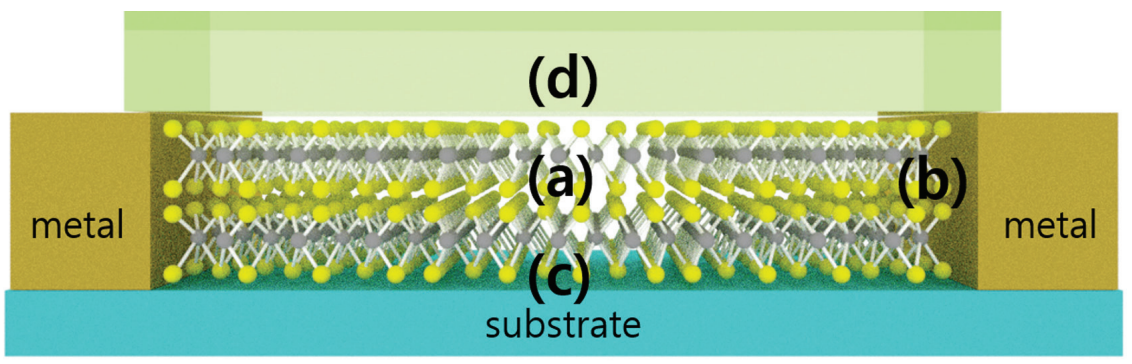

Fig. 1. Schematic diagram of 2D material-based photodetector including (a) 2D channel layer, (b) contact, (c) interface and (d) passivation layer.

에는 빛과 물질 사이의 상호 작용을 통해 입사된 광자를 전하 형태의 전기 신호로 변환할 수 있는 광 흡수 물질이 핵심 기술로 알려져 왔다. 그 중에서도 원자 두께 수준의 매우 얇은 2차원(2D, two-dimensions) 소재는 두께에 비해 광 흡수 계수가 상당히 크다. 또한, 층 수에 따라 광 전자 특성을 쉽게 제어할 수 있을 뿐만 아니라 투명하고 유연하지만 기계적 특성이 우수하여 플렉서블 광전자 분 야로도 유망하다. 밴드 갭(band gap)이 서로 다른 $2 \mathrm{D}$ 소 재를 활용하면 매우 좁은 영역의 파장의 빛을 선택적으로 검출하거나 또는 매우 넓은 영역의 빛 스펙트럼을 검출하 는 것이 모두 구현 가능하며, 특히, $2 \mathrm{D}$ 소재의 표면에는 댕글링 본드(dangling bond)가 없고 수직방향으로 약한 반데르발스(van der Waals) 결합으로 이루어져 있기 때 문에 격자 매칭에 제한없는 다양한 헤테로 접합 (heterojunction) 소자를 제작하는 것이 가능하다.

그래핀(graphene)은 가장 널리 알려진 2D 광 흡수 물질 중의 하나이다. 하지만 에너지 밴드 갭이 없어 암 전류(dark current)가 상당히 높으며 이는 광 소자의 검출 성능을 크게 저하시킨다. 최근 그래핀과 유사한 honeycomb 구조를 갖고 있으면서도 밴드 갭이 존재하 는 전이금속 디칼코게나이드(TMD, Transition Metal Dichalcogenides) 소재가 광 검출 소재로 주목받고 있 다. $2 \mathrm{D} \mathrm{TMD}$ 는 $\mathrm{MX}_{2}(\mathrm{M}$ : 전이금속, $\mathrm{X}$ : 칼코겐 $)$ 조성을 갖는 화합물로 층 수, 결정 구조, 원소 조성에 따라 다 양한 전기적 또는 광학적 특성을 갖는다. 예를 들면, $\mathrm{MoS}_{2}, \mathrm{MoSe}_{2}, \mathrm{WS}_{2}, \mathrm{WSe}_{2}, \mathrm{SnS}_{2}$ 와 같은 $\mathrm{TMD}$ 는 높은 캐리어 이동도(mobility)를 갖고 있으며 가시광선 스펙 트럼 범위에서 효율적인 광 흡수 특성을 이용한 광전자
소자에 응용이 가능하다. ${ }^{1-4)} \mathrm{TMD}$ 소재와 비슷한 에너 지 밴드 특성과 에너지 스펙트럼을 가지는 $\mathrm{BP}$ (Black Phosphorus)에 대한 광 특성 연구도 활발하게 진행되 었다. ${ }^{5,6)}$

광전 변환 효율은 광 흡수로 생성된 전자-홀 쌍(EHP, Electron Hole Pair)의 생성률과 이후 분리된 전하들의 이동의 용이성에 의존한다. 그리고 광 소자의 검출 성능 을 나타내는 필수적인 성능 지수는 응답성 $(\mathrm{R}$ : Responsivity), 검출도(D: Detectivity), 응답속도( $\tau$ : Response time) 등이 있으며 특히, R과 D 지수는 다음 과 같이 정의된다: $\mathrm{R}=\mathrm{I}_{\text {photo }} / \mathrm{P}_{\text {light }}, \mathrm{D}=\left(\mathrm{RA}^{1 / 2}\right) /\left(2 \mathrm{eI}_{\text {dark }}\right)$. 광 검출 소자의 성능에 영향을 미치는 요소는 매우 다양하기 때문에 Fig. 1의 소자 구조에서처럼 $2 \mathrm{D}$ 소재 채널 (channel), 컨택(contact), 계면(interface), 보호 층 (passivation layer)과 같은 중요한 요소 기술들에 대해 서 순차적으로 설명할 것이다. 구체적으로, 최근에 연구 가 가장 활발하게 진행되고 있는 2D 헤테로 구조(hetero structure) 채널 층의 광 특성 연구 동향에 대해 설명하 고 $2 \mathrm{D}$ 소재와 전극과의 컨택 기술, 기판과 $2 \mathrm{D}$ 소재와의 계면 최적화 기술, 마지막으로 $2 \mathrm{D}$ 소재 위에 보호 층 적 용 기술에 대한 연구 동향에 대해 기술하였다.

\section{2D 헤테로 구조 기반 광 센서}

일반적으로 단일 $2 \mathrm{D} \mathrm{TMD}$ 소재를 이용하여 매우 높은 감도를 가지거나 또는 넓은 파장의 빛을 검출하는 특성을 갖는 소자를 구현하는데 한계가 있다. 이는 $2 \mathrm{D}$ 소재의 광 흡수 특성이 두께에 상당히 민감하여 제어하기 쉽지 않으 


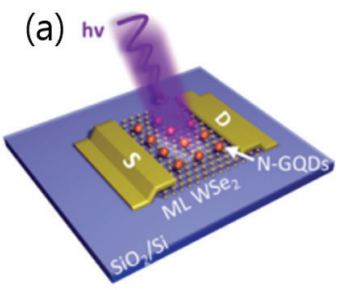

(b)

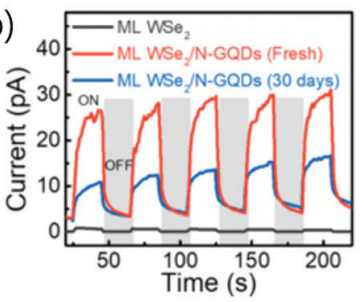

(e)

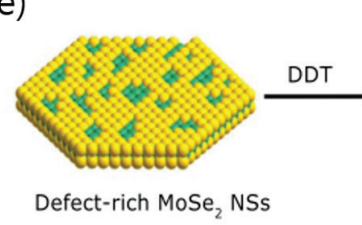

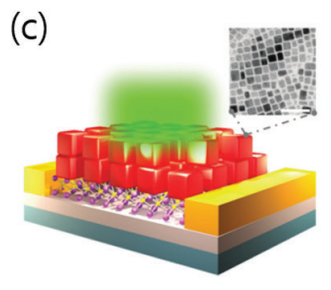

(d)

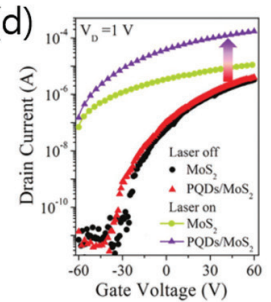

(f)

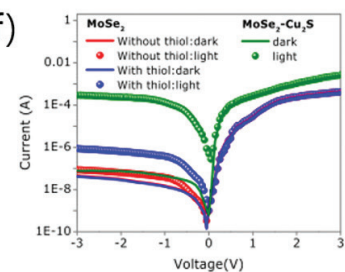

Fig. 2. (a) Schematic illustration of an ML(monolayer) WSe $/ \mathrm{N}-\mathrm{GQD}$ photodetector. ${ }^{11)}$ (b) Time-dependent photocurrent of $M L$ WSe (black line) and $\mathrm{ML} \mathrm{WSe} / \mathrm{N}-\mathrm{GQD}$ devices after fabrication (red line) and after 30 days under ambient (blue line) at VDS = $1 V$ and $V G=O V^{111}$ (c) Schematic model of the PQDs/MoS 2 device and its inset shows a typical TEM image of the PQDs. ${ }^{14)}$ (d) Transfer characteristics for pristine $\mathrm{MoS}_{2}$ and PQDs/MoS 2 hybrid phototransistors both in dark and under illumination of 532nm at $\mathrm{VD}=1 \mathrm{~V}$. ${ }^{14)}(\mathrm{e})$ Schematic illustration of the synthesis of $\mathrm{MoSe}_{2}-\mathrm{Cu}_{2} \mathrm{~S}^{15)}(\mathrm{f}) \mathrm{Semi}-\log$ plots of the current-voltage characteristics of $\mathrm{MoSe}_{2} \mathrm{NSs}$ (Nanosheets) with and without thiol(DDT), $\mathrm{MoSe}_{2}-\mathrm{Cu}_{2} \mathrm{~S}$ in the dark and under illumination of a $514 \mathrm{~nm}$ laser source. ${ }^{15)}$

며 단일 밴드 갭이 흡수할 수 있는 빛의 스펙트럼 범위 또 한 제한적이기 때문이다. 반면, 서로 다른 광학적 특성을 갖는 소재 간의 하이브리드(hybrid)화는 광 특성 엔지니 어링을 상당히 용이하게 만든다. 서론에서 언급한 것처럼 반데르발스 결합력으로 적층 된 $2 \mathrm{D}$ 소재는 다양한 차원 $(0,1,2,3$ 차원 $)$ 의 소재와 이종 헤테로 구조를 만들기 쉬 울 뿐만 아니라 특정 $2 \mathrm{D}$ 소재가 가지고 있는 고유 결정 방위나 에너지 밴드 갭 값에 상관없이 완전히 새로운 광 학 특성을 발현하는 것이 가능해진다. 일반적으로 $2 \mathrm{D}$ 헤 테로 구조는 층간 반데르발스 결합으로 이루어진 수직 구 조와 횡 방향에서 공유결합으로 이루어진 수평 구조로 나 뉘며 하이브리드 후보 물질은 금속, 반도체, 절연체에 이 르기까지 매우 다양하다. ${ }^{7)}$ 수직 구조는 트랜스퍼 (transfer) 같은 적층 공정을 적용해 쉽게 제작이 가능한 반면, 횡 방향 헤테로 구조 소자는 비교적 합성이 어려워 구현하기 쉽지 않다. 하지만 층 내에서 캐리어 이동이 용 이해 광 응답속도가 상당히 빠른 장점이 있다. ${ }^{8,9)}$

\subsection{D-OD 수직 헤테로 구조 광 센서}

$2 \mathrm{D}$ 소재는 높은 흡수 계수 값에도 불구하고 원자 층 수 준의 얇은 두께로 인해 빛에 대한 흡수 및 방출 능력에 대
한 물성 한계치가 존재한다. 이런 한계점을 극복하기 위 한 다양한 접근법이 존재한다. 예를 들면, $\mathrm{PL}$ (photoluminescence) 특성을 향상시키기 위해 결함 을 제어하거나 플라즈몬 공명 효과를 도입하는 방식이다. 또는, $\mathrm{QDs}(\mathrm{Quantum} \mathrm{Dots})$ 를 이용하여 2D 물질과 하이 브리드화 하는 방식이 있다. 특히, $2 \mathrm{D}$ 반도체는 다른 0 차 원 소재와 헤테로 구조를 형성하는 것이 쉽고 이종 물질 간 에너지 밴드 엔지니어링을 통해 전하 수송 거동과 광 특성을 손쉽게 변화시킬 수 있다. 최근 밴드 갭이 다른 콜 로이드 퀀텀닷(CQDs: Colloidal Quantum Dots)을 활 용하여 빛 검출 감도, 검출 속도, 그리고 스펙트럼 범위 를 향상시킨 $2 \mathrm{D}$ 광 소자 연구가 진행되었다. 예를 들면, p형 WSe2 반도체 표면 위에 그래핀 퀀텀닷(GQDs, Graphene Quantum Dots)을 코팅하여 광 검출 능력을 향상시킨 연구가 있다. GQD는 용액 공정을 통해 낮은 공 정 비용으로 제작이 가능해 다양한 $2 \mathrm{D}$ 반도체 소재에 적 용이 가능하다. ${ }^{10)}$ 한편, 성균관대학교 연구팀은 질소가 도핑 된 그래핀 퀀텀닷(N-GQDs, Nitrogen-doped Graphene Quantum Dots)으로 덮인 2D WSe $\mathrm{W}_{2}$ 헤테로 구조를 개발했다(Fig. $2 \mathrm{a}$ ). 개발 된 소자는 단일 층 $\mathrm{WSe}_{2}$ 보다 $480 \%$ 높은 광 응답성과 30 일 이후에도 $46 \%$ 의 성능 
(a)

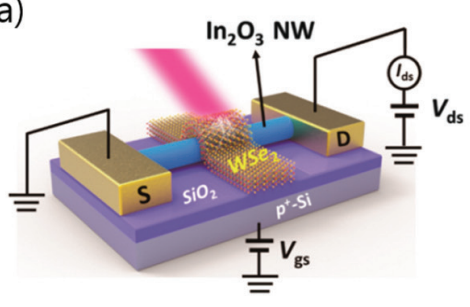

(d)

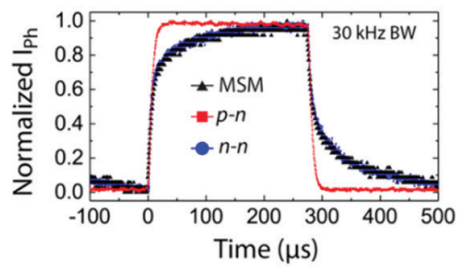

(b)

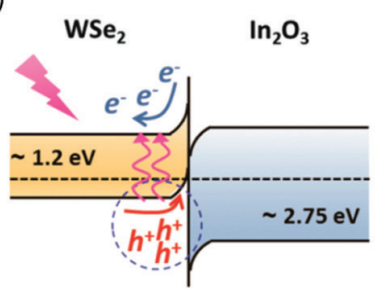

(e)

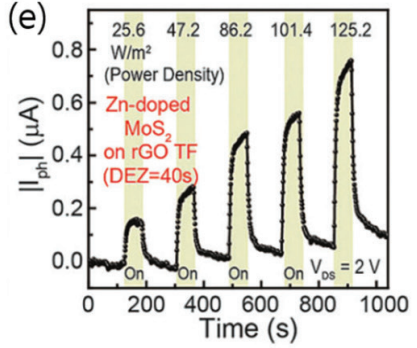

(c)

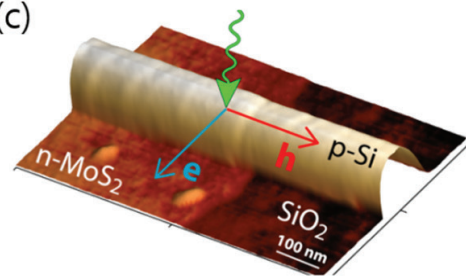

(f)

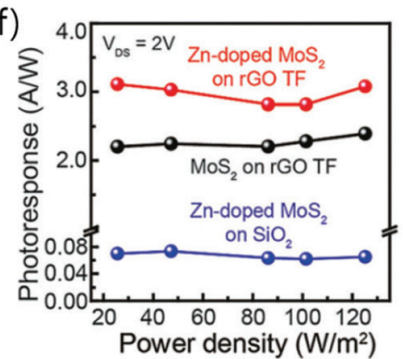

Fig. 3. (a) Schematic illustration of the Multilayer $\mathrm{WSe}_{2}-\mathrm{In}_{2} \mathrm{O}_{3} \mathrm{NW}$ (Nanowire) phototransistor. ${ }^{16)}$ (b) Energy band diagram at the junction formed by the $\mathrm{WSe}_{2}-\mathrm{In}_{2} \mathrm{O}_{3} \mathrm{NW}$. ${ }^{16)}$ (c) AFM topography of the $\mathrm{SiO}_{2} \mathrm{NW}^{17)}$ (d) Transient photocurrent for $\mathrm{p}-\mathrm{n}$ heterojunction (red squares), $n-n$ heterojunction (blue circles), and MSM devices (black triangles) acquired with a temporal resolution of 12us (30 $\mathrm{kHz}$ bandwidth) at $\mathrm{V}_{\mathrm{D}}=-8 \mathrm{~V}^{\text {(7) }}$ (e) Time-dependent photocurrent of the photodetector as a function of light intensity. ${ }^{18)}$ (f) The photoresponse of the photodetector based on the $\mathrm{MoS}_{2}-\mathrm{rGO}$ film (black), Zn-doped MoS $\mathrm{S}_{2}-\mathrm{rGO}$ film (red), and Zn-doped MoS layer (blue). ${ }^{18)}$

을 유지하는 우수한 광 특성 결과를 보여주었다(Fig. 2b). ${ }^{11)}$ 단일 층의 $\mathrm{WS}_{2}$ 와 $\mathrm{PbS} \mathrm{CQDs}$ 을 이용한 헤테로 구 조는 적외선 영역에서 $200 \mu \mathrm{s}$ 의 빠른 응답시간을 보여 주었다. ${ }^{12)}$ 한편, 화중 과학기술대학교 연구팀이 개발한 $\mathrm{PbS} / \mathrm{WSe}_{2}$ 광 소자는 $7 \times 10^{13}$ Jones의 우수한 검출도와 $2 \times 10^{5} \mathrm{~A} / \mathrm{W}$ 의 높은 응답성을 보여주었다. ${ }^{13)}$ 이외에도, 페로브스카이트(perovskite) $\mathrm{CsPbI}_{3-\mathrm{X}} \mathrm{Br}_{\mathrm{X}} \mathrm{QD}$ 의 우수한 광 흡수 특성을 이용하는 $\mathrm{MoS}_{2}$ 헤테로 구조가 제안되었 으며(Fig. 2c), 개발된 헤테로 소자는 단일 $\mathrm{MoS}_{2}$ 광 소자 보다 15 배 정도 높은 광 전류 특성을 보여주었다(Fig. 2d). ${ }^{14)}$ 인도델리공과대학교 연구팀은 $\mathrm{DDT}$ (Dodecanethiol)를 S 공급원으로 활용하여 $\mathrm{MoSe}_{2}$ 표면 에 존재하는 $\mathrm{Se}$ 결함 위에 $\mathrm{Cu}_{2} \mathrm{~S}$ island를 성장시켜 광 응 답성이 우수한 $\mathrm{p}-\mathrm{n}$ 접합 광 센서 소자를 개발하였다(Fig. 2e). ${ }^{15)}$ 관련 소자는 기존 $\mathrm{MoSe}_{2}$ 와 비교하여 3500 배 높은 광 특성을 보여주었고 온/오프 비율은 26배나 향상되었 다(Fig. 2f).

\subsection{D-1D 수직 헤테로 구조 광 센서}

나노 튜브(nanotube) 또는 나노와이어(nanowire)와
같은 1 차원 반도체는 $2 \mathrm{D} \mathrm{TMD}$ 소재와 쉽게 접합이 가능 해 광 검출 소자로 응용될 수 있다. Fig. 3a에서 나타낸 것처럼 $\mathrm{In}_{2} \mathrm{O}_{3}$ 나노와이어를 채널로 하고 그 위에 $\mathrm{WSe}_{2}$ 나노시트(nanosheet)를 전사함으로써 $\mathrm{WSe}_{2} / \mathrm{In}_{2} \mathrm{O}_{3} 2 \mathrm{D}$ 1D 헤테로 구조의 포토트랜지스터(phototransistor)가 제작되었다. ${ }^{16)} \mathrm{WSe}_{2}$ 와 $\mathrm{In}_{2} \mathrm{O}_{3}$ 의 독특한 에너지 밴드 정렬 로 인해 극도로 낮은 암전류 $\left(\sim 10^{-14} \mathrm{~A}\right)$ 를 가지며 높은 응 답성 $\left(\sim 10^{4} \mathrm{~A} / \mathrm{W}\right)$ 과 검출도 $\left(\sim 10^{17} \mathrm{Jones}\right)$ 가 확보된 광 센 서 소자가 구현되었다(Fig. $3 \mathrm{~b}$ ). 또한 상대적으로 작은 밴드갭을 갖고 있는 다층 $\mathrm{WSe}_{2}$ 로 인해 광 검출 파장 영 역이 가시광선에서 근적외선까지 넓어졌다. 또다른 $2 \mathrm{D}-$ $1 \mathrm{D}$ 광 센서 연구로 $\mathrm{p}-\mathrm{Si}$ 나노와이어에 다층 $\mathrm{MoS}_{2}$ 를 접 합하여 형성된 헤테로 구조의 광 특성 결과를 보고하였으 며 특히 기존에 보고된 bulk $\mathrm{Si} / \mathrm{MoS}_{2}$ 구조의 광 반응 응 답시간보다 10 배 이상 빠른 우수한 광 특성을 보였다 (Fig. 3c, d). ${ }^{17)}$ 한국화학연구원 연구팀은 1 차원 환원 그 래핀산화물(rGO, reduced Graphene Oxide) fiber와 $2 \mathrm{D} \mathrm{MoS}_{2}$ 소재로 이루어진 플렉서블(flexible) 광 센서 소 자를 개발하였으며 특별히 metalloporphyrin층을 이용 하여 $\mathrm{MoS}_{2}$ 에 $\mathrm{Zn}$ 을 도핑함으로써 광 검출기의 성능을 더 
(a)

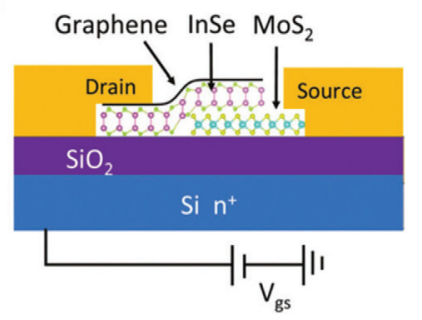

(c)

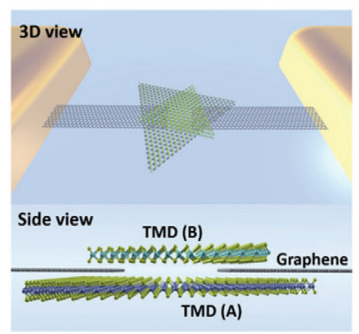

(b)

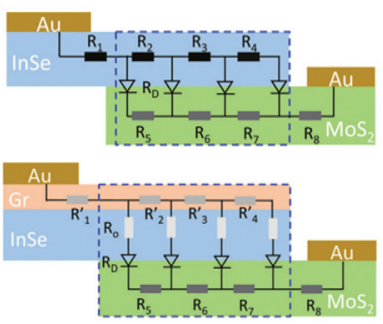

(d)

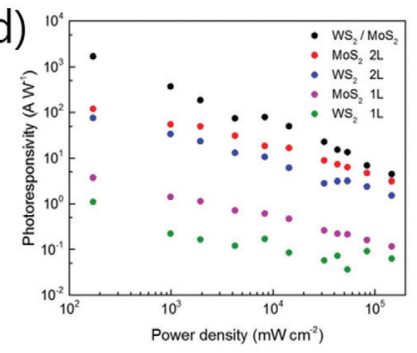

Fig. 4. (a) Schematic of a graphene/InSe/MoS 2 photodetector. ${ }^{21)}$ (b) Schematics of the simplified device models based on InSe/MoS 2 and graphene/InSe/MoS 2 heterostructures. ${ }^{21)}$ (c) Schematic 3D and side views of Gr $-\mathrm{WS}_{2} / \mathrm{MoS}_{2}-$ Gr photodetector. ${ }^{24)}$ (d) Photoresponsivity versus irradiation power. ${ }^{24)}$

욱 향상시켰다(Fig. $3 \mathrm{e}-\mathrm{f}) .{ }^{18)} 1$ 차원 나노 소재를 $2 \mathrm{D}-1 \mathrm{D}$ 헤테로 구조의 광 센서 소자로 활용하는 이유는 서로 다 른 이종 물질로 인한 밴드 엔지니어링이 가능할 뿐만 아 니라 1차원 소재의 독특한 양자역학적인 에너지 상태를 이용하여 광 검출 특성을 향상시키는 것이 가능하기때문 이다. 또한 관련 헤테로 광 센서 소자를 유연 기판에 제작 하면 플렉서블 광 센서 플랫폼을 구축하는 것이 용이해진 다. 그럼에도 불구하고, bottom-up공정으로 합성된 1차 원 소재를 $2 \mathrm{D}$ 소재와 쉽게 어레이(array) 형태로 집적화 할 수 있는 재현성 있는 공정이 개발되어야 상업화 기술 로 활용이 가능할 것이다.

\section{$2.32 \mathrm{D}-2 \mathrm{D}$ 수직 헤테로 구조 광 센서}

일반적으로 $2 \mathrm{D}$ 소재는 다른 $2 \mathrm{D}$ 소재들과 하이브리드 하여 2D-2D 수직 헤테로 구조 형태로 적층하여 제작하 는 것이 훨씬 수월한것으로 알려져있다. 동일 차원의 평 평한 플랫폼 위에 $\mathrm{Si}-\mathrm{CMOS}$ (Complementary Metal Oxide Semiconductor)공정을 적용하여 집적화하는 공 정을 적용하기도 훨씬 유리하다. 이 때문에 대부분의 $2 \mathrm{D}$ 소재 기반의 헤테로 소자 연구는 $2 \mathrm{D}-2 \mathrm{D}$ 형태로 적층된
형태를 띠고 있다.

광학적 이방성(anisotropic)을 가지고 있는 $\mathrm{BP}$ 소재와 $\mathrm{MoS}_{2}$ 를 수직 방향으로 적층한 헤테로 접합 포토다이오 드(photodiode)가 제작되었고 이전에 보고된 $\mathrm{BP}$ 로만 이 루어진 포토트랜지스터보다 $10^{2} \sim 10^{3}$ 배 더 빠른 빛 검출 반응 속도를 보여주었다. ${ }^{19)}$ 한편, $2 \mathrm{D} \mathrm{TMD} \mathrm{소재의} \mathrm{밴드}$ 갭은 주로 가시광선 스펙트럼 범위에 제한되어있기 때문 에 이런 한계점을 극복하기 위해 $\mathrm{p}-\mathrm{WSe}_{2} / \mathrm{n}-\mathrm{MoS}_{2}$ 헤테 로 구조 사이에 그래핀을 위치시킨 $\mathrm{p}-\mathrm{g}-\mathrm{n}$ 헤테로 구조 광 센서가 새롭게 제안되었다. ${ }^{20)}$ 관련 광 센서 소자는 근 적외선 범위에서 최대 $10^{11}$ Jones 검출 능력을 가지고 있었으며 광대역 스펙트럼 검출 소자로 응용이 가능하였 다. 단일 층의 $n-\mathrm{MoS}_{2}$ 위에 다층의 $\mathrm{n}-\mathrm{InSe}$ 을 전사하고 최종 상부에는 그래핀을 덮어 광 센서 소자가 보고되었다 (Fig. 4a). ${ }^{21)}$ 이 구조는 그래핀과 n-InSe간의 오믹 컨택 (ohmic contact)을 통해 접합 특성을 향상시켰으며 그래 핀의 효율적인 전하 이동 특성으로 인해 재결합을 최소화 시킬 수 있었다(Fig. 4b). 또한 그래핀 층은 외부 대기와 의 접촉을 막는 보호층으로 기능하여 한달 동안 광 전류 특성이 거의 변하지 않는 안정적인 소자 특성을 구현할 
(a)

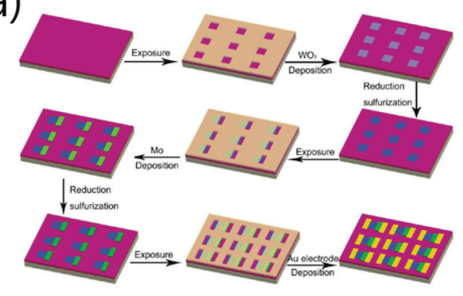

(c)

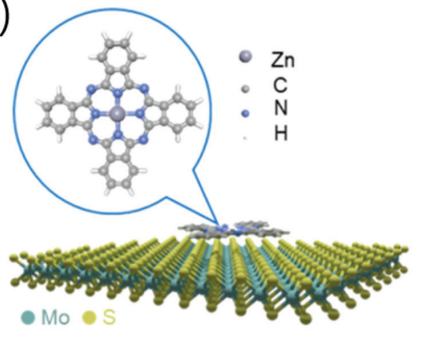

(b)

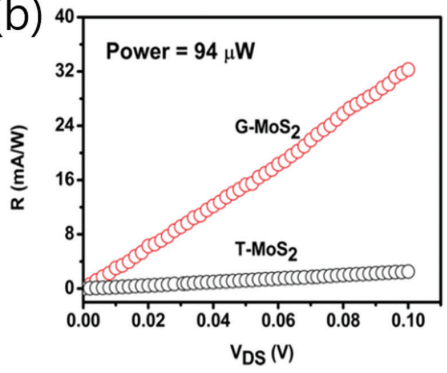

(d)

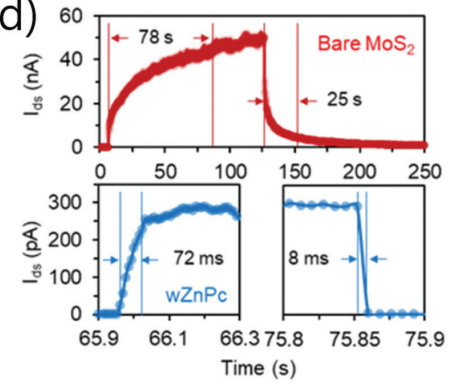

Fig. 5. (a) Schematic diagram of $\mathrm{MoS}_{2} / \mathrm{WS}_{2}$ vertical heterojunction preparation and corresponding devices fabrication. ${ }^{27)}$ (b) Responsitivity as a function of $V_{D S}$ from 0 to $0.1 \mathrm{~V}$ under the light irradiation at $94 \mu \mathrm{W} .{ }^{28)}$ (c) Schematic illustration of a flat-lying ZnPc molecule on monolayer $\mathrm{MoS}_{2}{ }^{31}$ (d) The time-dependent photoresponse dynamics for a $\mathrm{MoS}_{2}$ device after varied $\mathrm{ZnPc}$ treatments are plotted in the respective linear scale. ${ }^{31}$

수 있었다.

성균관대학교 연구팀은 초소형 나노 graphene/h-BN (hexagonal Boron Nitride)/1L- $\mathrm{MoS}_{2}$ 로 구성된 새로운 MIS(Metal Insulator Semiconductor) 다이오드 구조 를 개발했으며 MIS구조는 $\mathrm{MS}$ 기반 다이오드보다 전하 이동에 대한 장벽 높이가 커서 암전류를 상당히 낮출 수 있었다. ${ }^{22)}$ 옥스포드대학교 연구팀은 화학기상증착법 (CVD, Chemical Vapor Deposition)으로 합성된 2D 나 노소재를 이용하여 graphene- $\mathrm{WS}_{2}$-graphene 헤테로 광 소자를 개발하였다. ${ }^{23)}$ 또한, Fig. $4 \mathrm{c}$ 에서 보이는 것처 럼 $\mathrm{WS}_{2} / \mathrm{MoS}_{2}$ 헤테로 구조에 그래핀을 사이에 접촉시켜 고성능 포토트랜지스터를 제작하였으며, ${ }^{24)}$ 개발된 헤테 로 소자는 TMD 단일 소자에 비해 광 응답성이 상당히 개 선될 수 있음을 보도하였다(Fig. $4 \mathrm{~d}$ ). 관련 연구들은 모 두 이종 소재내 반데르발스 갭을 통한 전하 이동을 제어 함으로써 궁극적으로 광 센서 소자의 성능을 크게 향상시 켰다. 서로 다른 이종 소재의 계면 상태를 최적화하기 위 한 방법으로 가장 선호되는 공정법은 epitaxial 증착 방
법이다. 단일 층의 $\mathrm{MoS}_{2}$ 기판 위에 CVD를 이용하여 $\mathrm{CdS}$ 를 epitaxial 성장시킨 $\mathrm{CdS} / \mathrm{MoS}_{2}$ 헤테로 구조가 최 근 보고되었다. 일반적으로 CVD epitaxial 성장은 결정 방위와 적층 구조를 정밀하게 제어할 수 있어 $2 \mathrm{D}$ 소재 적 층공정에서 빈번하게 사용된다. $\mathrm{CdS} / \mathrm{MoS}_{2}$ 광 검출 소자 는 넓은 스펙트럼 영역의 파장을 검출하는 것이 가능하였 으며 광 응답 속도 역시 50배 향상되었다. ${ }^{25)}$ 유사한 방 법으로 후난대학교 연구팀은 CVD epitaxial 성장을 활용 하여 대면적 $\mathrm{WSe}_{2} / \mathrm{SnS}_{2} \mathrm{p}-\mathrm{n}$ 접합을 제작하여 광 검출 성능을 측정해본 결과, 매우 깨끗한 계면 특성 때문에 $500 \mu \mathrm{s}$ 의 빠른 광 응답속도와 $10^{-14} \mathrm{~A}$ 의 매우 낮은 암전 류 값을 확보하였다. ${ }^{26}$

$2 \mathrm{D}$ 헤테로 구조를 제작하기 위해서 성장 공정이 상당 히 중요해지는데 한 종류의 프리커서(precursor)를 미리 증착하는 방식이 공정 용이성 및 소자 집적화 측면에서 유리하다. 쑤저우대학교 연구팀은 TRSP(Thermal Reduction Sulfurization Process)를 통해 $\mathrm{MoS}_{2} / \mathrm{WS}_{2}$ 의 주기적으로 배열된 패턴 소자들을 제작하였다(Fig. 
5a). ${ }^{27)} \mathrm{TRSP}$ 는 먼저 감광제(photoresist)를 이용하여 기 판 위에 Square hole들을 배열시킨 후 그 hole에 $\mathrm{WO}_{3}$ 를 열 증착하고 마지막으로 CVD 챔버에 황 분말을 넣어 $\mathrm{WS}_{2}$ 나노시트를 형성하는 합성법이다. 유사하게 $\mathrm{Mo}$ 금 속을 열 증착하여 $\mathrm{MoS}_{2}$ 나노시트를 $\mathrm{WS}_{2}$ 와 겹치게 합성 한 방법이 보고되었는데 이 방법은 시트의 크기, 밀도, 형 상을 원하는 대로 조절할 수 있어 대용량 어레이 소자를 쉽게 만들 수 있는 장점이 있다. 그래핀 위에 bilayer $\mathrm{MoS}_{2}$ 를 저기압 화학기상증착법(LPCVD, Low Pressure Chemical Vapor Deposition)을 이용하여 센티미터 스 케일의 균일한 필름을 성장시켜 헤테로 구조를 완성한 연 구도 보고되었다. ${ }^{28)}$ Ttransfered $\mathrm{MoS}_{2}$ 보다 LPCVD로 합성한 growing $\mathrm{MoS}_{2}$ 에서 고감도 빛 반응 특성을 보였 으며 40 번의 사이클 평가에서도 안정적인 광 특성 결과 를 보여주었다(Fig. 5b).

새로운 $2 \mathrm{D}$ 소재 기반의 반데르발스 헤테로 구조 연구 도 활발하게 진행되고 있다. 예를 들면, $\mathrm{p}-\mathrm{GaTe} / \mathrm{n}-\mathrm{MoS}_{2}$ 헤테로 구조 소자에서 $\mathrm{GaTe}$ 는 intrinsic한 p형 반도체 소재이며 두께 상관없이 직접천이형 밴드 갭(direct band gap)을 가지고있어 고효율 광 특성 구현에 유리하 다. ${ }^{29)}$ 개발된 소자는 자가 구동이 가능하며 전자 및 정공 들로 인해 ambipolar 거동을 보여주었다. ${ }^{30)}$ 또 다른 연 구로 Fig. 5 c에서와 같이 단일 층 $\mathrm{MoS}_{2}$ 와 $\mathrm{ZnPc}$ (Zinc Phthalocyanine) 유기 분자를 결합하여 제작한 반데르 발스 헤테로 구조가 있다. ${ }^{31)} \mathrm{ZnPc}$ 분자쪽으로 정공을 유 도시켜 PPC(persistent photoconductance)를 억제해 궁극적으로 순수한 $\mathrm{MoS}_{2}$ 소자에 비해 응답속도가 상당히 향상되었다(Fig. $5 \mathrm{~d}$ ). 런던대학교 연구팀은 전사 기법을 통해 MGH ( $\mathrm{MoS}_{2} /$ Glassy-graphene Heterostructure) 기반의 투명 광 검출기를 개발하였다. ${ }^{22)}$ 일반적으로 $\mathrm{MoS}_{2}$ 와 그래핀의 접촉은 쇼트키 컨택(schottky contact) 이지만 glassy-graphene을 사용하여 전하 이동 장벽을 낮추어 오믹 컨택이 형성되게 하였다. 그 결과로 전하 이 동을 향상시켜 고성능 광 센서 특성이 구현되었다. $\mathrm{MoTe}_{2} / \mathrm{MoS}_{2}$ 헤테로 구조에서 서로 다른 극의 게이트 전 압을 인가해주면 전압에 따라 소자 특성이 달라지는 것을 확인했으며 이 구조는 적외선 영역에서 광 응답 특성을
나타내어 투명 적외선 센서로 활용이 가능할 것이다. ${ }^{33)}$

\subsection{D-3D 수직 헤테로 구조 광 센서}

일반적으로 기존에 가장 많이 활용되는 3차원 벌크 플 랫폼은 $2 \mathrm{D}$ 소재와 융합되기 가장 손쉬운 소재이기때문에 2D-3D 헤테로 구조 광 센서 연구 또한 상당히 많은 연 구가 진행 되었다. 단순하게는 3 차원 반도체 위에 $2 \mathrm{D}$ 소 재를 적층하여 $\mathrm{p}-\mathrm{n}$ 포토다이오드를 구현한 것과 $\operatorname{MSM}($ Metal Semiconductor Metal) 구조를 포토컨덕터 (photoconductor) 또는 포토트랜지스터로 활용한 연구 가 있다.

2D/3D 헤테로 구조를 갖는 포토다이오드는 기존의 $3 \mathrm{D} / 3 \mathrm{D}$ 포토다이오드와 비교하여 얇은 $2 \mathrm{D}$ 층상 물질을 이용하기 때문에 접합 면까지 빛 에너지가 도달할 가능성 이 증가해 광 검출 특성이 향상되는 장점이 있다. 또한, $2 \mathrm{D}$ 와 $3 \mathrm{D}$ 소재 사이의 물리적 접합부는 공유결합으로만 형성된 기존의 실리콘 $\mathrm{p}-\mathrm{n}$ 접합과는 완전히 다른 에너지 밴드 프로파일을 가질 것으로 예측된다. 이에 부응하여 라이스대학교 연구팀은 단일 층 $\mathrm{n}-\mathrm{MoS}_{2} / \mathrm{p}-\mathrm{Si}$ 헤테로 접합에 대한 새로운 3 차원 밴드 다이어그램을 제시하고 외부 전압이 인가된 상황에서의 전하 흐름을 규명하였 다. ${ }^{34)}$ 한편, 상업적으로 활용이 가능한 $2 \mathrm{D} / 3 \mathrm{D}$ 헤테로 접 합 포토다이오드를 구현하기 위해서는 광 검출 면적이 넓 어야 하기 때문에 top-down 방식의 스카치테이프 박리 법을 통한 전사보다는 bottom-up 방식의 대면적 합성 법이 요구된다. 최근 재료연구소와 충북대학교 공동연구 팀은 대기압 플라즈마 화학기상증착법(AP-PECVD, Atmospheric Pressure Plasma Enhanced Chemical Vapor Deposition)을 이용하여 $\mathrm{MoS}_{2} / \mathrm{p}-\mathrm{Si}$ 및 $\mathrm{WS}_{2} / \mathrm{p}$ $\mathrm{Si}$ 헤테로 구조 포토다이오드를 제작하였다(Fig. 6a). ${ }^{35)}$ 이 합성법은 고품위의 $2 \mathrm{D} \mathrm{TMD}$ 소재를 대기압 저온 $\left(\sim 200^{\circ} \mathrm{C}\right)$ 에서 매우 빠르게 성장시킬 수 있을 뿐만 아니 라 유연한 $\mathrm{PET}$ 기판 위에도 직접적으로 합성을 가능하게 하였다. 이 외에도 용액 공정을 이용하여 아민기가 있는 폴리스티렌 $\left(\mathrm{PS}-\mathrm{NH}_{2}\right)$ 으로 개질한 $\mathrm{MoSe}_{2}$ 나노시트를 물 표면에 분산시킨 후 용매 증발을 이용해 균일한 두께의 $\mathrm{MoSe}_{2}$ 복합 필름을 합성하는 연구도 진행되었다(Fig. 
(a)

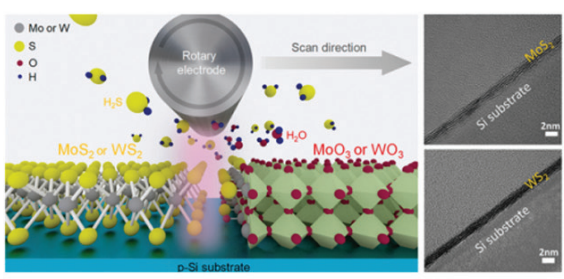

(d)

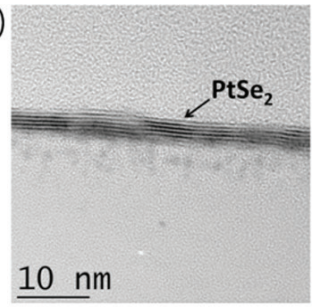

$(\mathrm{e})_{3}$

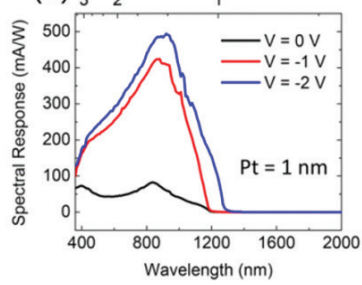

(b)

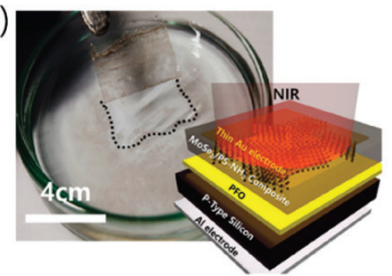

(f)

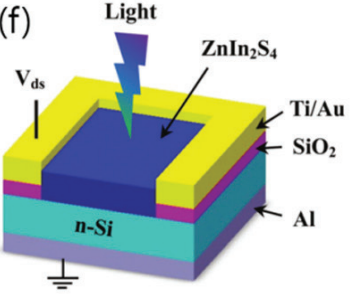

(c)

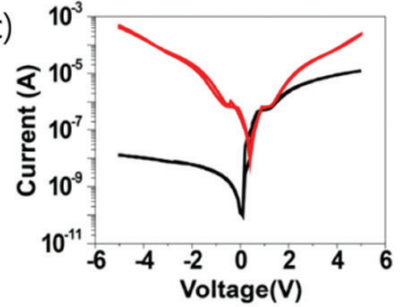

(g)

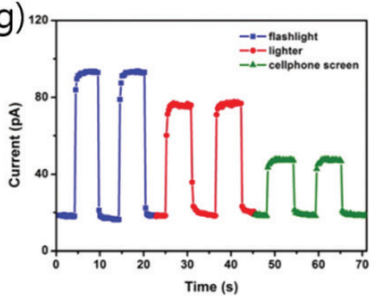

Fig. 6. (a) Schematic illustration of plasma synthesis reaction mechanism between $\mathrm{H}_{2} \mathrm{~S}$ molecules and $\mathrm{MoO}_{3}$ (or $\mathrm{WO}_{3}$ ) film. And $\mathrm{High}-$ resolution cross-sectional TEM image of an $\mathrm{MoS}_{2}$ multilayer on Si substrate. ${ }^{35}$ (b) MoSe $/$ /PS- $\mathrm{NH}_{2}$ nanocomposite film was readily transferred on a substrate, the schematic illustration shows an individual MoSe $2 / \mathrm{PS}-\mathrm{NH}_{2}$ photodiode. ${ }^{36)}$ (c) Log scale currentvoltage characteristics of a $\mathrm{p}-\mathrm{n}$ junction vertical photodiode with a MoSe $2 / \mathrm{PS}-\mathrm{NH}_{2}$ film before (black) and upon NIR exposure (red). ${ }^{36)}$ (d) Cross-sectional TEM image of the PtSe $e_{2}$ selenized from Pt layer ${ }^{40)}$ (e) Absolute spectral response plots of the PtSe $/ \mathrm{n}-$ Si Schottky barrier diodes under various reverse DC biases. ${ }^{40)}(\mathrm{f})$ Schematic description of a $\mathrm{ZnIn}_{2} \mathrm{~S}_{4} / \mathrm{Si}_{\text {i photodetector. }}{ }^{41)}(\mathrm{g})$ Photoswitching behavior of the $\mathrm{Zn} \ln _{2} \mathrm{~S}_{4} / \mathrm{Si}$ device under weak signal excitation. ${ }^{41)}$

$6 \mathrm{~b}, \mathrm{c}) .{ }^{36)} \mathrm{MoSe}_{2}$ 복합 필름은 p형의 poly $(9,9-\mathrm{di}-\mathrm{n}-$ octylfluorenyl-2,7-diyl) 또는 $\mathrm{p}-\mathrm{Si}$ 기판에 손쉽게 전 사될 뿐만 아니라 $\mathrm{PET}$ 기판에도 적용해 플렉서블한 광 검 출 디바이스를 구현하였으며 1000회 굽힘 테스트 후에도 일정하게 성능이 유지되었다. 또한 용액기반으로 합성된 $\mathrm{MoSe}_{2} / \mathrm{Si}$ 헤테로 접합 광 센서는 $32 \mathrm{MHz}$ 이상의 $3 \mathrm{~dB}$ 예 측 대역폭에서 $30 \mathrm{~ns}$ 의 매우 빠른 응답 속도를 보여주 었다. ${ }^{37)}$

인천대학교 연구팀은 기존보다 진보된 구조의 헤테로 접합 포토다이오드를 고안하였다. ${ }^{38)} \mathrm{CVD}$ 로 합성된 3 층 의 $\mathrm{MoS}_{2}$ 를 이용하여 $\mathrm{MoS}_{2} / \mathrm{n}-\mathrm{Si} / \mathrm{p}-\mathrm{Si}$ 광 센서 소자를 제작하였고 이 광 센서 소자는 두개의 정류 접합을 갖는 특이한 구조로 되어있어 우수한 광 응답성과 $30 \mu \mathrm{s}$ 의 빠 른 반응시간을 보여주었다. 또 다른 방법으로 기상증착법 (vapor phase deposition)을 이용하여 성장시킨 다층 $\mathrm{WS}_{2}$ 를 $\mathrm{p}-\mathrm{Si}$ 에 단순히 적층하는 방법을 통해 고성능 제 너(zener) 포토다이오드를 개발하였다. ${ }^{39)}$ 보고된 결과에 의하면 $2 \mathrm{D}$ 소재 기반 제너 포토다이오드는 상업적으로 이용 가능한 $\mathrm{Si}$ 포토다이오드보다 우수한 광 응답성을 가 지기 때문에 고성능 광 검출기로서 잠재적인 활용이 가능
할 것으로 판단된다.

최근에 새로운 $2 \mathrm{D}$ 소재들을 이용한 포토다이오드 연구 들이 발표되고 있다. $2 \mathrm{D}-\mathrm{PtSe}_{2}$ 는 벌크에서 단일 층으로 두께가 얇아질수록 반금속(semimetal) 특성에서 반도체 성질로 물성이 바뀌게 되고 상대적으로 작은 밴드 갭으로 인해 적외선 검출이 가능하다. $\mathrm{PtSe}_{2}$ 를 $400{ }^{\circ} \mathrm{C}$ 이하의 저 온에서 CVD 공정을 통해 대면적으로 합성하여 제작한 $\mathrm{PtSe}_{2} / \mathrm{n}-\mathrm{Si}$ 헤테로 포토다이오드는 넓은 파장 영역의 빛 을 검출할 수 있는 광 특성을 보여주었다(Fig. $6 \mathrm{~d}$, e). ${ }^{40)}$ 최근에는 고품위의 $2 \mathrm{D}-\mathrm{ZnIn}_{2} \mathrm{~S}_{4}$ 나노시트를 간단한 습 식 화학방법으로 합성하여 $\mathrm{ZnIn}_{2} \mathrm{~S}_{4} / \mathrm{n}-\mathrm{Si}$ 포토다이오드 어레이를 제작한 연구가 진행되었다(Fig. 6f). ${ }^{41)}$ 개발된 광 센서 소자는 $\mathrm{ZnIn}_{2} \mathrm{~S}_{4} / \mathrm{n}-\mathrm{Si}$ 의 우수한 계면 전하 이동 특성 덕분에 매우 낮은 암전류( 18 pA) 값과 우수한 신 호 대 잡음비(SNR, signal-to-noise ratio) 특성을 보 여주었다(Fig. 6g).

2D-3D포토다이오드 외에 MSM 구조 기반의 포토컨 덕터 또는 포토트랜지스터를 제작한 연구가 있다. 3D 물 질을 광 검출 액티브(active) 채널로 이용하고 $2 \mathrm{D}$ 물질을 헤테로 접합한 연구가 진행되었는데, 예를 들면, $\mathrm{RF}$ 스 
(a)

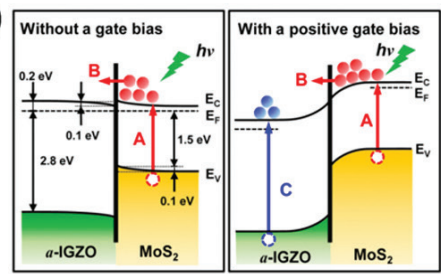

(d)

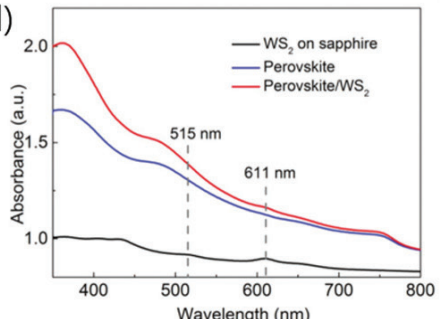

(b)

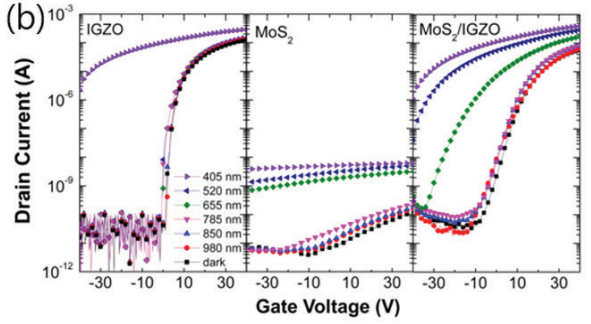

(e)

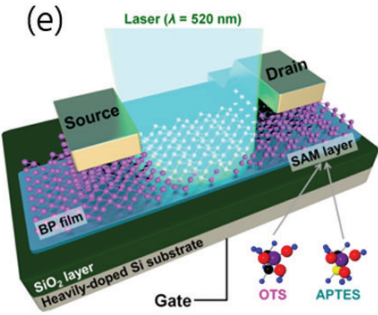

(c)

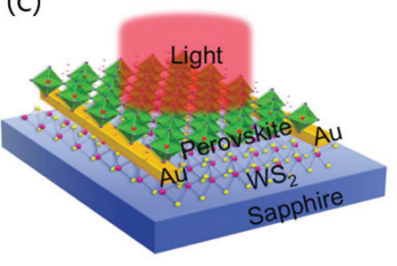

Fig. 7. (a) Schematic illustrations showing the energy band alignment and the photoinduced charge transfer mechanism of the heterostructured MoS $/$ a-IGZO stack without (left) or with (right) an applied positive gate bias. ${ }^{42)}(\mathrm{b})$ Transfer characteristics $\left(\mathrm{V}_{\mathrm{D}}=10 \mathrm{~V}\right)$ of aIGZO, MoS 2 , and MoS$/$ a-IGZO phototransistors as a function of the illuminating light wavelength at a fixed optical power $(0.5 \mathrm{~mW})$. ${ }^{42}$ (c) Schematic device structure of the hybrid WS $/$ perovskite photoconductor fabricated on a C-plane (0001) sapphire substrate. ${ }^{44)}$ (d) UV - Vis absorption spectra for the pristine $W_{2}$, perovskite, and heterostructured WS 2 /perovskite samples. ${ }^{44)}$ (e) Schematic illustration of $S A L$-doped BP photodetector under laser illumination $\left(P_{\text {light }}=6 \mathrm{~mW} / \mathrm{cm}^{2}\right)$ and descriptive diagram showing the changes of photocarrier recombination in (i) APTES- and (ii) OTS-doped BP films. ${ }^{48)}(\mathrm{f}) \mathrm{I}_{\text {photo }}-\mathrm{V}_{\mathrm{G}}$ characteristics of the undoped (dotted line) and APTES (pink solid line)/OTS (green solid line)-doped BP photodetectors. ${ }^{48)}$

퍼터링으로 증착한 비정질 $\mathrm{IGZO}(\mathrm{InGaZnO})$ 필름 위에 용액기반으로 간편하게 합성한 $\mathrm{MoS}_{2}$ 를 전사 시켜 대면 적의 $\mathrm{MoS}_{2} / \mathrm{IGZO}$ 포토트랜지스터 구조를 제안하였다. ${ }^{42)}$

$\mathrm{IGZO}$ 와 $\mathrm{MoS}_{2}$ 소재가 가지고 있는 서로 다른 밴드 갭 특 성 때문에 자외선부터 가시광선까지 넓은 영역의 빛을 검 출하는 것이 가능하였다(Fig. 7a, b). 유사하게 스퍼터링 된 비정질 $\mathrm{IGZO필름} \mathrm{위에} \mathrm{스카치} \mathrm{테이프로} \mathrm{박리한} \mathrm{MoS}_{2}$ flake를 올려 $\mathrm{MoS}_{2} / \mathrm{IGZO}$ 헤테로 구조의 포토트랜지스 터를 제작하였다. ${ }^{43)}$ 개발된 헤테로 구조의 소자는 $\mathrm{MoS}_{2}$ 층이 없는 IGZO 광 검출 소자보다 무려 5 배 높은 광 응 답성을 보여주었다. 다층 $\mathrm{MoS}_{2}$ 는 가시광선을 흡수하여 전자를 생성시키고 $\mathrm{IGZO}$ 필름은 생성된 전자를 이동시키 는 층으로 사용되어 자외선부터 근적외선까지의 광대역 파장을 가지고 있는 빛의 검출을 가능하게 하였다.

반대로 $2 \mathrm{D}$ 소재를 광 흡수 액티브 채널로 활용하고 $3 \mathrm{D}$ 물질은 헤테로 접합을 형성하는데 이용된 광 센서 소자 연구 또한 활발히 진행되었다. KAUST 연구팀은 단층 $\mathrm{WS}_{2}$ 와 광 흡수 특성이 뛰어난 페로브스카이트 $\mathrm{CH}_{3} \mathrm{NH}_{3} \mathrm{PbI}_{3}$ 소재를 하이브리드하여 고성능 광 검출 소
자를 개발하였다(Fig. $7 \mathrm{c}, \mathrm{d}){ }^{44}$ 광 검출 소자의 암전류 크기뿐만 아니라 재결합 특성이 현저하게 억제되어 최종 적으로 광 전류는 10 배 상승하였고 단층 $\mathrm{WS}_{2}$ 의 높은 이 동도 특성과 수평방향으로의 뛰어난 전하 분리 특성에 의 해 응답속도 역시 $10^{4}$ 배 증가하였다.

최근 $2 \mathrm{D} / 3 \mathrm{D}$ 플랫폼에서 도핑이나 결함 특성을 이용하 여 광 센서 특성을 향상시킨 연구가 진행되었다. 성균관 대학교 연구팀은 $\mathrm{PPh}_{3}$ (Triphenylphosphine) 를 이용하 여 $\mathrm{h}-\mathrm{BN}$ 층 상에 제조 된 $\mathrm{p}-\mathrm{WSe}_{2}$ 를 $\mathrm{n}$ 형으로 도핑시킨 광 센서 연구 결과를 발표하였다. ${ }^{45)}$ 또한 $\mathrm{BP} / \mathrm{MoO}_{3}$ 및 $\mathrm{BP} / \mathrm{Cs}_{2} \mathrm{CO}_{3}$ 헤테로 구조를 통해 각각 $\mathrm{p}$ 형과 $\mathrm{n}$ 형 도핑이 되는 것을 확인하였고 궁극적으로 응답속도가 향상 된 광 센서 소자를 구현하였다. ${ }^{46)}$ 이와 유사하게 2D TMD에 자 가 조립 단분자막(SAM, Self Assembled Monolayer)을 이용하여 헤테로 구조를 구현한 연구가 최근 발표되었 다. ${ }^{47)} \mathrm{OTS}$ (octadecyltrichlorosilane)는 $\mathrm{WSe}_{2}$ 를 $\mathrm{p}$ 형으 로 도핑 시키기 때문에 28.2배 향상된 응답성을 보였으 며 APTES(aminopropyltriethoxysilane)는 n-type 도 핑 시키기 때문에 $\mathrm{MoS}_{2}$ 기반 헤테로 구조 광 센서의 응 
(a)

Step I: PLD growth of $\mathrm{Bi}_{2} \mathrm{Te}_{3}$ nanofilm

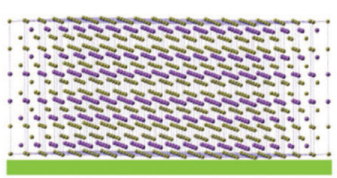

(b)

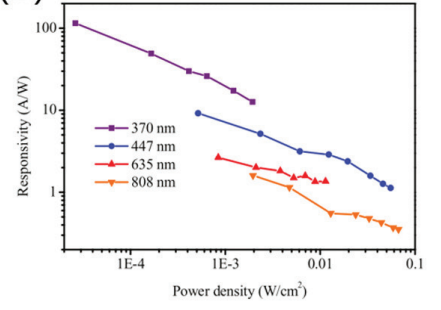

Step II: FIB etching for separated $\mathrm{Bi}_{2} \mathrm{Te}_{3}$ electrodes

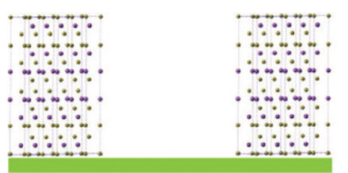

(c)

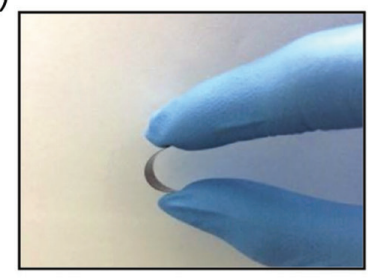

Step III: PLD growth of SnS

photosensitive channel

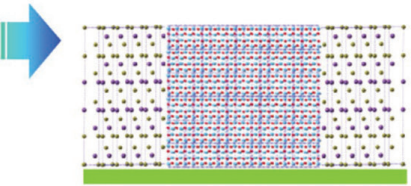

(d)

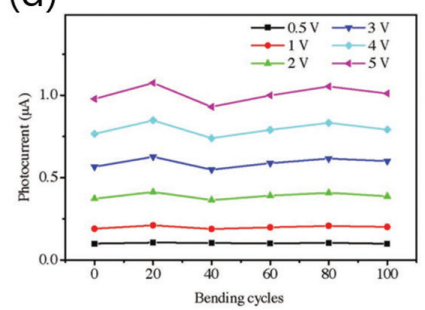

Fig. 8. (a) Schematic diagram illustrating fabrication process of all-2D $\mathrm{Bi}_{2} \mathrm{Te}_{3}-\mathrm{SnS}_{-}-\mathrm{Bi}_{2} \mathrm{Te}_{3}$ photodetector. (b) Power density dependent responsivity upon 370, 447, 635, and 808nm illumination (source-drain voltage: $5 \mathrm{~V}$ ). (c) A typical digital photograph of a bended $\mathrm{Bi}_{2} \mathrm{Te}_{3}-\mathrm{SnS}-\mathrm{Bi}_{2} \mathrm{Te}_{3}$ photodetector. (d) Photocurrent of the device upon different bend cycles. ${ }^{52}$

답성을 26.4배 향상시켰다. 동일 연구 그룹은 $\mathrm{BP}$ 에 $\mathrm{APTES}$ 를 이용한 $\mathrm{n}$-type 도핑시 광 검출 퍼포먼스가 줄 어드는 반면 OTS를 이용한 p-type 도핑 시 광 검출 퍼 포먼스가 눈에 띄게 향상된다는 것을 보고하였다(Fig. $7 \mathrm{e}-\mathrm{f}){ }^{48)}$ 다른 한편으로, 결함 특성을 제어하는 연구로 단층의 $\mathrm{WSe}_{2}$ 에 레이저 빔을 조사해 healing 한 후 페로 브스카이트 물질을 얇게 코팅해주면 단일 층의 $\mathrm{WSe}_{2}$ 광 센서 소자 대비 $10^{3}$ 배 이상의 성능이 향상된다는 것을 보 고하였다. ${ }^{49)}$

\subsection{D 소재 기반 수평 헤테로 구조 광 센서}

광 센서 소자의 경우 응답성, 검출도, 응답 속도와 같은 성능 지수를 증가시키는 것이 중요하다. $2 \mathrm{D}$ 적층 헤테로 구조에서 발생하는 반데르발스 갭을 통한 전하 이동 보다 는 횡 방향의 공유결합을 통해 전하가 이동하면 빛의 검 출 속도를 크게 증가시킬 수 있다. CVD 합성법을 통해 제 조된 대면적 수직 구조인 graphene/ $\mathrm{MoS}_{2}$ 소자에 비해 동일 평면상에 제조된 수평 $2 \mathrm{D}-2 \mathrm{D}$ 헤테로 구조의 graphene/ $\mathrm{MoS}_{2}$ 소자에서 더 큰 정류 특성을 보여주었 다. ${ }^{50)}$ 또한, 화중과학기술대학교 연구진은 $\mathrm{CVD}$ 를 이용 하여 $\mathrm{MoS}_{2}$ 와 $\mathrm{WS}_{2}$ 가 횡 방향으로 epitaxial하게 연결된
수평 헤테로 구조를 처음으로 제안하였고 이 소자는 외부 바이어스 없이도 $\mathrm{EHP}$ 가 빠르게 분리되는 덕분에 4.36 $\mathrm{mA} / \mathrm{W}$ 의 높은 광 응답성과 $4.36 \times 10^{13} \mathrm{Jones}$ 의 높은 검 출도 값을 보여주었다. ${ }^{51)}$ 한편, $\mathrm{PLD}(\mathrm{Pul}$ sed Laser Deposition) 방식으로 $\mathrm{Bi}_{2} \mathrm{Te}_{3}$ 나노 필름을 만들고 일부를 FIB(Focus Ion Beam) 공정으로 일부를 에칭(etching) 시킨 후 다시 $\mathrm{PLD}$ 를 이용하여 에칭 된 부분에 $\mathrm{SnS}$ 를 성 장시켜 $\mathrm{Bi}_{2} \mathrm{Te}_{3}-\mathrm{SnS}-\mathrm{Bi}_{2} \mathrm{Te}_{3}$ 소자를 완성하였다(Fig. 8a). ${ }^{52)}$ 이 구조에서 $\mathrm{SnS}$ 부분에서 빛을 흡수하여 생성된 전하들은 $\mathrm{SnS} / \mathrm{Bi}_{2} \mathrm{Te}_{3} / \mathrm{Ti}$ 계면 전극을 통해 손쉽게 이동 하는 작동 방식으로 광 검출 특성을 나타내었다. 자외선 부터 근적외선 영역까지 검출이 가능할 뿐만 아니라 100 회 동안 우수한 내구성을 보여주었다. $2 \mathrm{D}$ 금속 전극과 반 도체 채널을 횡 방향으로 합성시켜 All- $2 \mathrm{D}$ 소재 기반의 플렉서블 광 센서가 구현되었다(Fig. $8 \mathrm{~b}-\mathrm{d}$ ).

2D-2D 수평 구조 광 센서뿐만 아니라 2D-3D 구조의 광 센서에 대한 연구도 진행되었다. 기존 벌크 단결정 $\mathrm{Si}$ 과 횡 방향으로 연결되는 헤테로 구조를 이루기 위해서는 $\mathrm{Si}$ 위에 $2 \mathrm{D}$ 소재 물질을 수직으로 증착해야 한다. 예를 들어, Fig. $9 \mathrm{a}$ 처럼 대면적 성장이 가능한 스퍼터링법을 이용하여 $\mathrm{p}-\mathrm{Si}$ 위에 수직 방향으로 $\mathrm{WS}_{2}$ 를 증착하여 
(a)

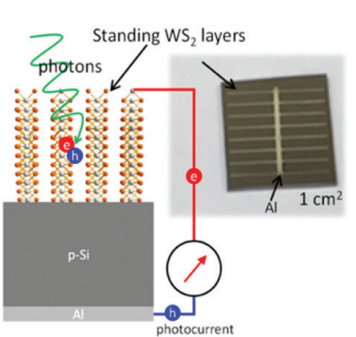

(d)

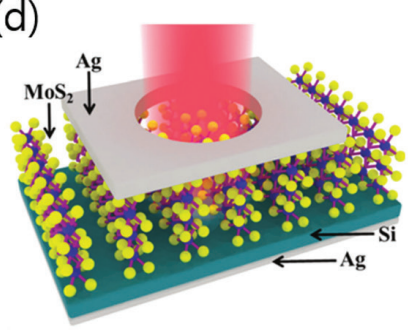

(b)

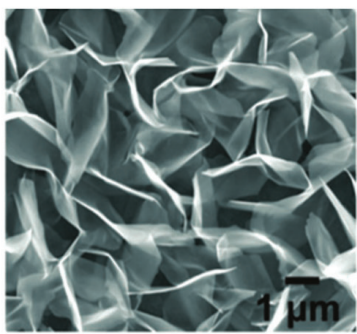

(e)

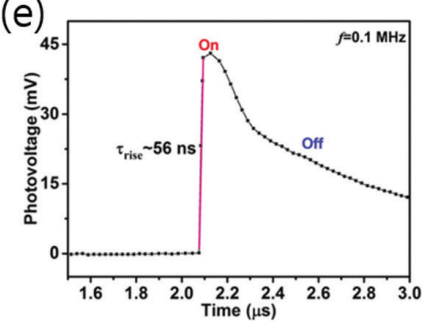

(c)

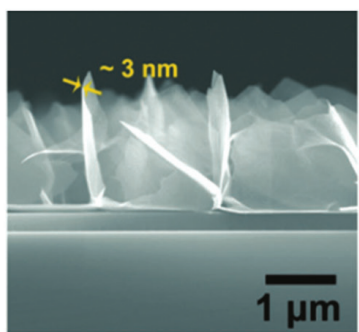

(f)

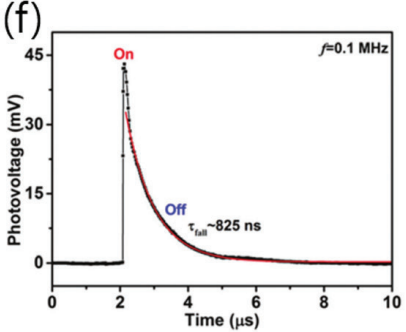

Fig. 9. (a) Schematic and photograph of the sputtering based WS $/$ p-Si heterojunction device (an active area of $\left.1 \mathrm{~cm}^{2}\right)^{\text {9) }}$ (b) Top-down and (c) cross-sectional SEM images of vertical-MoS 2 . (d) Schematic illustration of the photoresponse of the vertical-MoS $/$ Si heterojunction device. ${ }^{8)}$ The magnified plots of one response cycle for $0.1 \mathrm{MHz}$ at laser $(\mathrm{e})$ being turned on and (f) being turned off. ${ }^{8)}$

$\mathrm{WS}_{2} / \mathrm{Si}$ 수평 헤테로 구조를 제작하였다. ${ }^{9)} 2 \mathrm{D} \mathrm{WS}$ 의 높 은 캐리어 이동도로 인하여 $1.5 \times 10^{10}$ Jones의 높은 검출 성능을 보여주었다. 또, 다른 연구진은 $\mathrm{CVD}$ 를 공정을 이 용하여 수직 방향의 $\mathrm{MoS}_{2}\left(\mathrm{~V}-\mathrm{MoS}_{2}\right.$, Vertically oriented few layered $\mathrm{MoS}_{2}$ ) 나노시트를 합성 후 $\mathrm{Si}$ 기판 위에 전 사하였다(Fig. $9 \mathrm{~b}-\mathrm{d}){ }^{8)} \mathrm{V}-\mathrm{MoS}_{2} / \mathrm{Si}$ 헤테로 접합 광 센 서 소자는 $908.2 \mathrm{~mA} / \mathrm{W}$ 의 광 응답성과 $1.889 \times 10^{13}$ Jones의 검출도를 띄며 가시광선에서 근적외선까지의 넓은 광대역 검출을 가능하게 하였다. 관련 소자는 매우 빠른 광 스위칭 응답속도(rising time: $56 \mathrm{ns,} \mathrm{fall} \mathrm{time:}$ $825 \mathrm{~ns}$ )도 나타냈었다(Fig. 9e, f).

\section{3. $2 \mathrm{D}-$ 전극 접촉 물성 엔지니어링 연구}

$2 \mathrm{D}$ 기반의 광 센서 소자를 상업화하기 위해서 절대적 으로 필요한 부분은 광 특성의 신뢰성이다. 이런 광 센서 소자의 신뢰성을 향상시키기 위한 하나의 접근법은 $2 \mathrm{D}$ 액티브 채널 층과 금속 전극 사이에 발생하는 계면 결함 을 최소화하는 것이다. 일반적으로 광 생성 캐리어는 이 러한 결함에 쉽게 포획되고 결국 높은 접촉 저항을 유발
시켜 광 센서 소자의 성능을 크게 저하시킨다. 또한 2D전극 접촉면의 에너지 밴드 프로파일에 의해 생성된 광 전자의 거동이 달라지므로 적절한 엔지니어링 기술이 요 구된다.

$\mathrm{MoS}_{2}$ 와 금속 전극 사이 계면에 $\mathrm{TiO}_{2}$ 필름을 원자증착 법(ALD, Atomic Layer Deposition)법으로 형성한 포토 트랜지스터가 개발되었다(Fig. 10a). ${ }^{53)} \mathrm{TiO}_{2}$ 필름 도입은 페르미 레벨(fermi level) pining 현상을 해결해 컨택 저 항을 크게 감소시켰으며 궁극적으로 광 응답성 및 응답속 도를 현저히 향상시켰다(Fig. 10b). 한편, 채널과 금속 사 이의 중간 버퍼층으로 산화물을 사용하지 않고 $2 \mathrm{D}$ 소재 를 삽입해 컨택 저항을 줄인 연구도 진행되었다. $2 \mathrm{D}$ $\mathrm{WSe}_{2}$ 를 채널 물질로 사용하고 전극과의 컨택 층으로 $\mathrm{Nb}$-doped $\mathrm{WSe}_{2}$ 를 사용하면 2D/2D 오믹 컨택을 형성 할 수 있으며 이는 고성능 포토트랜지스터로 활용 가능하 다(Fig. 10c). ${ }^{54)} \mathrm{Nb}$-doped $\mathrm{WSe}_{2}$ 는 $\mathrm{WSe}_{2}$ 채널과 금속 전극을 연결하여 낮은 컨택 저항을 형성하고 광 조사 시 여기된 EHP의 수집 효율을 향상시킨다. 개발된 포토트 랜지스터는 상업용 $\mathrm{Si}$ 및 $\mathrm{InGaAs}$ 기반의 광 검출기와 비 슷하거나 또는 진공상태에서 더 높은 검출 능력( $10^{13}$ 
(a)

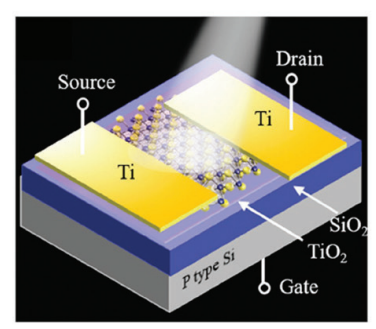

(d)

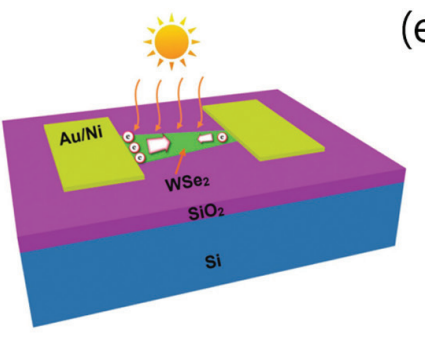

(b)

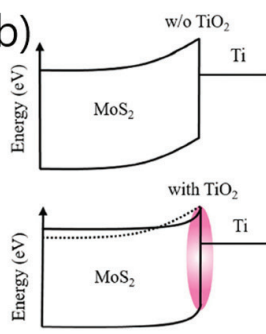

(e)

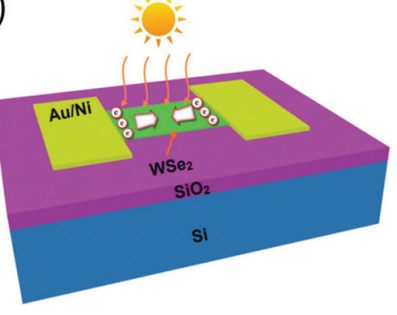

(c)

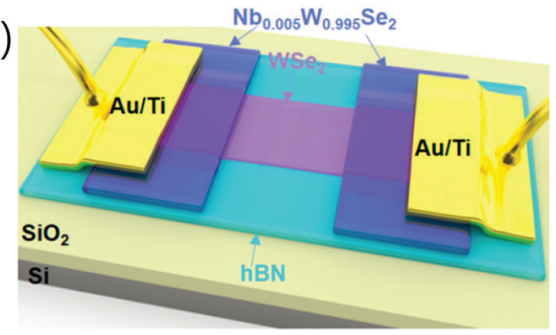

(f)

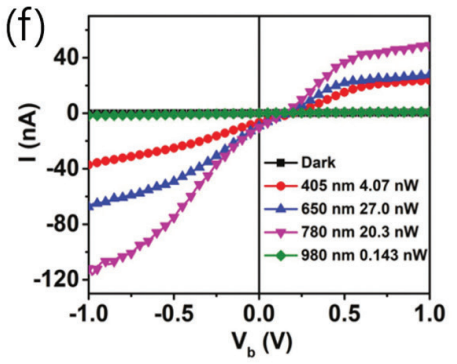

Fig. 10. (a) Schematic of an exfoliated $\mathrm{MoS}_{2}$ device with a $\mathrm{TiO}_{2}$ interlayer. ${ }^{53)}$ (b) The band diagram of the interface between $\mathrm{Ti}$ and

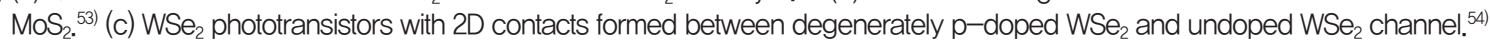
$(\mathrm{d}, \mathrm{e}) 3 \mathrm{D}$ schematic device structure of the metal-WSe $\mathrm{e}_{2}$-metal (MSM) photodetectors with asymmetric contact geometries, and symmetric contact geometries. A net current is generated when the $(d)$ device is illuminated by the light under zero bias for structure, (e) while no net current results under the same condition for structure. (f) Measured I- $V$ curves of asymmetric MSM photodetector under illumination at different light wavelengths. ${ }^{56)}$

Jones)을 나타내었다.

한편, 광 검출기의 접촉 저항을 줄이려는 연구 이외에 도 접촉면의 구조를 엔지니어링 하여 광 센서 소자의 검 출 성능을 향상시킨 연구도 진행되었다. $\mathrm{MoTe}_{2}$ 와 접촉하 는 소스 드레인 사이의 접촉면적이 서로 다른 비대칭 접 촉 형태의 $\mathrm{MoTe}_{2}$ 포토트랜지스터를 제안하였다. ${ }^{55)}$ 이런 비대칭 구조에서는 서로 다른 접합 특성 때문에 강한 광 전지 특성이 발생되어 빛 에너지만으로 자가 작동이 가능 한 광 센서를 구현 가능해진다. 유사하게 다른 연구진은 비대칭 접촉 구조를 갖는 $\mathrm{WSe}_{2}$ 소재 기반의 $\mathrm{MSM}$ 광 소 자를 제안하였다(Fig. $10 \mathrm{~d}$, e). ${ }^{56)}$ 관련 소자는 비대칭 접 촉 구조 덕분에 $\sim 1 \mathrm{fA}$ 의 극도로 낮은 암전류를 보여주며 기존의 광 검출기와 다르게 외부 전압이 없이도 작동이 가능한 자체 구동 광 센서로 활용이 가능하다(Fig. 10f).

\section{4. $2 \mathrm{D}$-기판 계면 물성 엔지니어링 연구}

일반적인 $\mathrm{SiO}_{2}$ 기판 위에 놓여진 $2 \mathrm{D}$ 소재의 고유 특성
을 발현시키는 것이 쉽지 않은데 이는 $\mathrm{SiO}_{2}$ 표면에 존재 하는 유기물 및 불순물 때문이다. ${ }^{57)}$ 특히 3 차원 소재에 비 해 원자 층 두께의 소재에서는 전하가 이동하는 유효 영 역이 $2 \mathrm{D}$ 평면 내로 한정되어 전하의 이동 특성은 기판 표 면 품질에 상당한 영향을 받게 된다. 이러한 이유로 단일 층의 $\mathrm{MoS}_{2}$ flake를 이용하지 않고 다층의 $\mathrm{MoS}_{2}$ 를 이용 하여 전하가 이동할 수 있는 유효 면적을 증가시킨 후 표 면 결함으로 인한 성능 저하를 최소화 시킨 연구결과를 얻기도 하였다. ${ }^{58)}$ 한편, 실리콘 산화물 기판 표면에 $\mathrm{h}-\mathrm{BN}$ 을 전사시켜 $2 \mathrm{D}$ 그래핀 및 $\mathrm{TMD}$ 의 전하 이동도를 획기적으로 향상시킨 연구결과가 보고되었다. ${ }^{59,60)}$ 댕글 링 본드가 없는 $\mathrm{h}-\mathrm{BN}$ 을 $2 \mathrm{D}$ 액티브 채널 층과 게이트 유 전체 사이에 삽입하여 전하 트랩을 감소시킴으로써 $2 \mathrm{D}$ 소재의 전계 효과 이동도가 크게 향상된 것이다. 이 방법 은 FET(Field Effect Transistor)뿐만 아니라 2D 물질 기반의 광 검출기에도 적용되었다. 예를 들면, $\mathrm{h}-\mathrm{BN}$ flake 위에 액티브 채널로 $\mathrm{WSe}_{2}$ 를 적층하여 포토트랜지 스터를 구현한 결과가 있으며, ${ }^{54} \mathrm{~h}-\mathrm{BN}$ 과 $\mathrm{MoS}_{2}$ 를 $\mathrm{RF}$ 마 
(a)

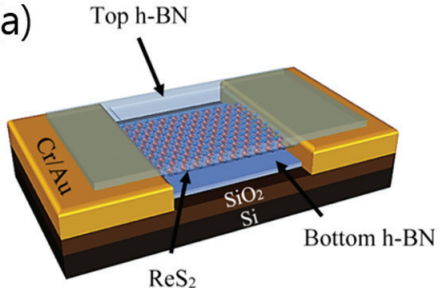

(d)

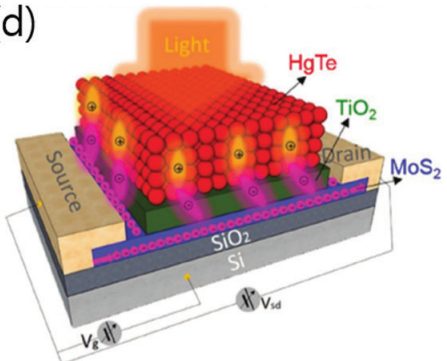

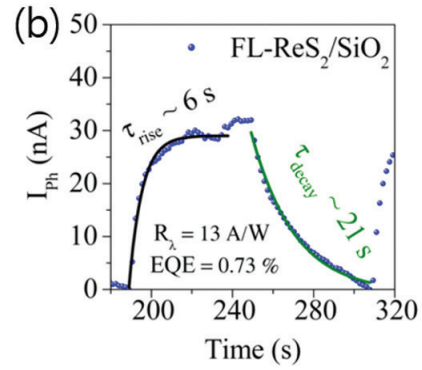

(e)

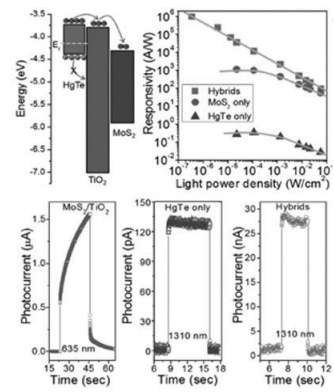

(c) 0.64

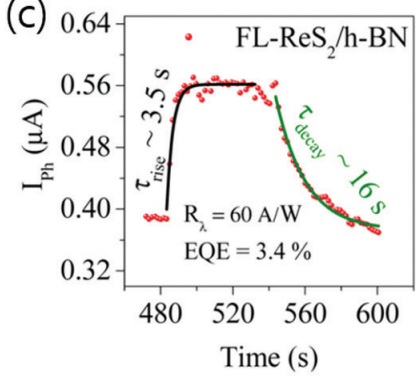

(f)

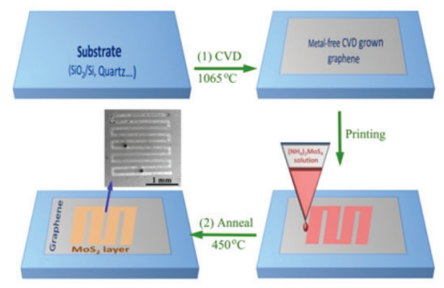

Fig. 11. (a) Schematic of the $\mathrm{h}-\mathrm{BN} / \mathrm{FL}-\mathrm{ReS}_{2} / \mathrm{h}-\mathrm{BN}$ device. ${ }^{62)}$ (b) $\mathrm{FL}-\mathrm{ReS}_{2} / \mathrm{SiO}_{2}$ and (c) FL-ReS $/ \mathrm{h}-\mathrm{BN}$ devices. ${ }^{62)}$ All measurements were performed in vacuum at room temperature. The $\mathrm{FL}-\mathrm{ReS}_{2}$ flakes have the same channel length of 6.8um with a width of 3.3um. (d) Schematic diagram of typical $\mathrm{MoS}_{2} / \mathrm{TiO}_{2} / \mathrm{HgTe}$ hybrid photodevice. ${ }^{64)}(\mathrm{e})$ Band alignment of $\mathrm{MoS}_{2}, \mathrm{TiO}_{2}$, and $\mathrm{HgTe}$ QDs, performing type- $\|$ band alignment at the $\mathrm{HgTe} / \mathrm{TiO}_{2}$ interface. Light power density dependence of the responsivity of $\mathrm{MoS}_{2}, \mathrm{HgTe}$ and hybrids photodetectors. Dynamic response of photocurrent in different devices with light wavelength of $635 \mathrm{~nm}$ and $1310 \mathrm{~nm} .{ }^{64)}(\mathrm{f})$ Schematic of the two-step transfer-free fabrication process for MoS $/$ graphene van der Waals heterostructures: (1) metal-free CVD growth of graphene directly on substrate and (2) printing the $\left(\mathrm{NH}_{4}\right)_{2} \mathrm{MoS}_{4}$ precursor on graphene followed by annealing to form 2D MoS 2 /graphene heterostructures. ${ }^{65}$

그네트론 스퍼터링법을 이용하여 $\mathrm{SiO}_{2}$ 기판 위에 $\mathrm{h}-\mathrm{BN}$, $\mathrm{MoS}_{2}$ 를 차례로 증착하여 대면적의 포토트랜지스터를 제 작한 연구결과도 보고되었다. ${ }^{61)}$ 유사하게, $\mathrm{WSe}_{2}$ 채널 아 래에 $\mathrm{h}-\mathrm{BN}$ 층을 삽입함으로써 계면에서의 산란 현상을 억제하여 높은 응답 속도와 빠른 스위칭 속도를 갖춘 $\mathrm{WSe}_{2}$ 기반 광 검출기 또한 구현되었다. ${ }^{45} \mathrm{SiO}_{2}$ 기판에 다 층 $\mathrm{ReS}_{2}$ 를 채널 물질로 사용하고 $\mathrm{h}-\mathrm{BN}$ 필름을 기판과 의 계면에 삽입한 $\mathrm{ReS}_{2}$ 포토트랜지스터에서 향상된 광 검출 특성이 보고되었다(Fig. 11a). ${ }^{62)}$ 최근 개발된 $\mathrm{ReS}_{2}$ $2 \mathrm{D}$ 소재는 벌크 형태에서도 직접 밴드 갭 특성을 보유하 고 있어 광 소자로 상당히 유망한 후보로 인식되었다. 추 가로 $\mathrm{h}-\mathrm{BN}$ 을 capping층으로 이용함으로써 다층 $\mathrm{ReS}_{2}$ 포토트랜지스터 소자의 $\mathrm{EQE}$ 값이 5 배 상승하였다(Fig. $11 b, c)$.

이 외에도 $\mathrm{h}-\mathrm{BN}$ 을 헤테로 접합 계면에 적용함으로써 광 센서 소자의 성능을 향상시킨 연구가 있다. 예를 들면,
graphene/h-BN/MoTe 2 구조의 다이오드 광 소자에서 $1145 \mathrm{~nm}$ 파장영역에서 강한 광 응답성을 보였으며 $\mathrm{h}-\mathrm{BN}$ 터널링 층(tunneling layer)으로 인하여 빠른 응답시간 과 극도로 낮은 암전류( $5 \mathrm{pA})$ 의 성능을 나타내었다. ${ }^{63)}$ 또한, 유사하게 $\mathrm{HgTe} C \mathrm{CQDs} / \mathrm{MoS}_{2}$ 헤테로 접합 계면에 터널링 층인 $\mathrm{TiO}_{2}$ 를 삽입한 구조의 포토트랜지스터가 개 발되었다(Fig. 11d). ${ }^{64)} \mathrm{HgTe} \mathrm{CQDs}$ 는 용액 공정으로 간 편하게 합성이 가능하고 적외선의 단파장부터 중파장까 지의 광 검출이 가능해 유망한 소재로 알려졌으나 낮은 이동도 및 광학 이득(optical gain)으로 인해 실제적으로 낮은 광 응답 특성을 보인다. 하지만 $\mathrm{TiO}_{2}$ 를 삽입한 구조 로 개발된 $\mathrm{MoS}_{2} / \mathrm{TiO}_{2} / \mathrm{HgTe} \mathrm{CQDs}$ 포토트랜지스터는 $\mathrm{HgTe} \mathrm{QD}$ 연구분야에서 발표된 결과치의 최고 광 응답 성을 나타내었다(Fig. 11e). 게이트 전압의 변조를 통해 노이즈 전류를 억제시킴으로써 $2 \mu \mathrm{m}$ 의 긴 파장영역에서 도 큰 검출도( $\left.10^{12} \mathrm{Jones}\right)$ 를 구현하는 것이 가능했다. 
(a)

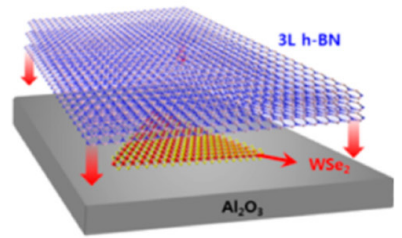

(c)
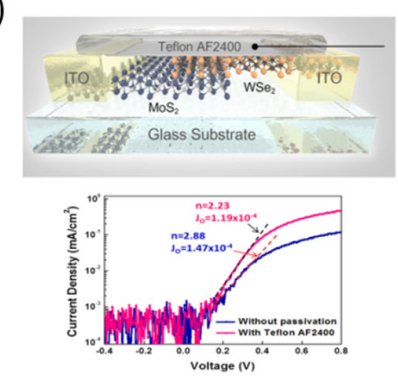

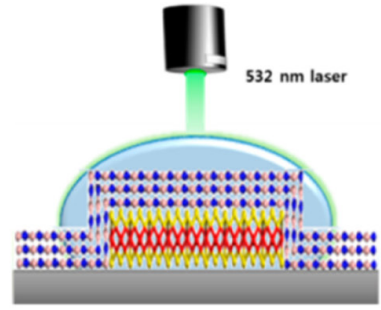

(d)
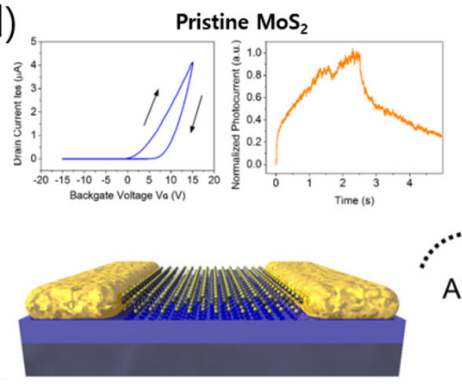

(b)
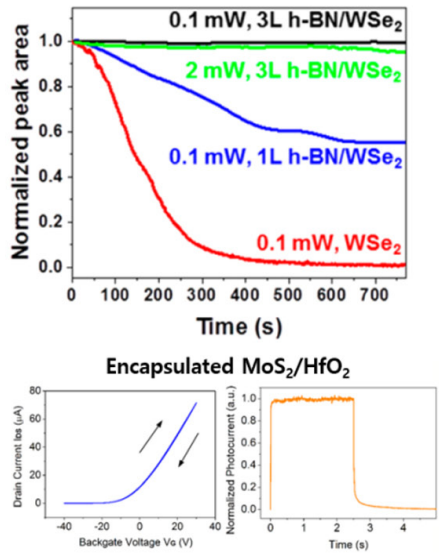

ALD

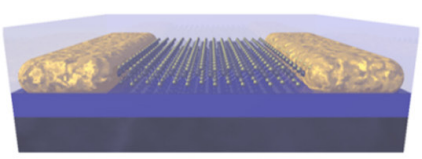

Fig. 12. (a) Schematic illustration outlining the preparation of $3 \mathrm{~L} h-\mathrm{BN} / \mathrm{WS} \mathrm{e}_{2}$ and exposure to the laser in the presence of a water

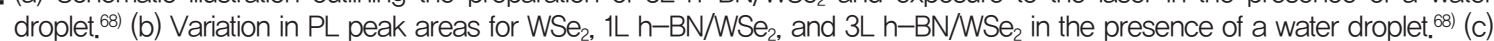
Schematic image of $\mathrm{WSe}_{2} / \mathrm{MoS}_{2}$ transparent solar cell and Teflon AF2400, a fluoropolymer that we have utilized as a passivation layer. $\mathrm{J}-\mathrm{V}$ characteristics under dark state and related diode parameters extracted from the fitted line for the initial device and the one with passivation. ${ }^{69)}(\mathrm{d})$ Transfer curve $\mathrm{IDS}_{\mathrm{S}}-\mathrm{V}_{\mathrm{G}}$, drain current during 1 cycle of light modulation for $\mathrm{MoS}_{2}$ devices, and a 3D sketch of $\mathrm{MOS}_{2}$ devices before and after ALD encapsulation. ${ }^{70)}$

한편, 합성된 $\mathrm{MoS}_{2}$ 층을 그래핀 위에 옮긴 것이 아닌 그 래핀 위에서 직접 성장시킨 transfer-free 합성을 이용 해 매우 깨끗한 인터페이스를 얻는 공정법이 개발되었 다. ${ }^{65)} \mathrm{CVD}$ 로 합성된 대면적의 graphene 위에 $\mathrm{MoS}_{2}$ 의 전구체 물질인 $\left(\mathrm{NH}_{4}\right)_{2} \mathrm{MoS}_{4}$ 솔루션을 프린팅 한 후 저온 에서 합성시켜 $\mathrm{MoS}_{2} / g r a p h e n e$ 광 검출 소자를 제작하 였다(Fig. 11f). 개발된 광 소자는 이전에 보고된 $\mathrm{MoS}_{2} /$ transfered-graphene 보다 높은 광 검출 성능을 띠고 있었으며 이는 광 소자에서 깨끗한 계면 특성이 상당히 중요함을 인지시키는 연구결과이다.

\section{5. 보호 층-2D 구조 기반의 광 특성 향상 연구}

$2 \mathrm{D}$ 나노 소재는 대기의 습기 또는 다른 기체 분자의 흡 착으로 인해 전기적, 광학적 특성이 상당히 변할 수 있다. 흡착된 분자는 표면 포획 사이트로 작용하거나 전하 이동 을 방해하는 요소로 작동한다. 이를 해결하기 위해서는 액티브 채널 층 위에 다양한 보호 층을 추가로 형성시키
는 간단한 전략이 매우 효과적이다.

최근 연구에 의하면 $\mathrm{TMD}$ 소재는 산소, UV 조사, 오 존, 대기중 가열에 의해 쉽게 분해 될 수 있다는 연구결과 가 보고되었다. ${ }^{66,67)}$ 이런 $2 \mathrm{D} \mathrm{TMD}$ 소재의 분해는 주로 결 정립계에서 먼저 시작하며 특히 $\mathrm{BP}$ 물질에서는 이런 현 상이 더욱 심각해진다. 울산과학기술대학교 연구팀은 레 이저 $(532 \mathrm{~nm})$ 노출에 의한 $\mathrm{WSe}_{2}$ 및 $\mathrm{MoSe}_{2}$ 의 광분해와 $\mathrm{h}-\mathrm{BN}$ 보호 층에 의한 광분해 방지 효과에 대한 최근 연 구결과를 보고하였다(Fig $12 \mathrm{a}){ }^{68)} \mathrm{WSe}_{2}$ 의 광분해는 레이 저 출력이 $0.5 \mathrm{~mW}$ 이상에서는 빠르게 발생했으며 $0.1 \mathrm{~mW}$ 미만에서는 관찰되지 않았다. 그러나, $\mathrm{WSe}_{2}$ 표 면에 물방울이 존재하면 $\mathrm{WSe}_{2}$ 의 광분해는 더욱 가속될 뿐만 아니라 $0.1 \mathrm{~mW}$ 에서도 일어났다. $\mathrm{h}-\mathrm{BN}$ 으로 $\mathrm{WSe}_{2}$ 를 encapsulation하면 광 분해를 효과적으로 방지할 수 있다는 것을 발견했다(Fig. 12b). 또한, $\mathrm{h}-\mathrm{BN}$ 기판 위에 $\mathrm{ReS}_{2}$ 를 채널물질로한 $\mathrm{FL}$ (Few Layer) $-\mathrm{ReS}_{2} / \mathrm{h}-\mathrm{BN}$ 포 토트랜지스터와 그 위에 $\mathrm{h}-\mathrm{BN}$ 층을 추가로 적층한 $\mathrm{h}-\mathrm{BN} / \mathrm{FL}-\mathrm{ReS}_{2} / \mathrm{h}-\mathrm{BN}$ 포토트랜지스터의 광 검출 성 


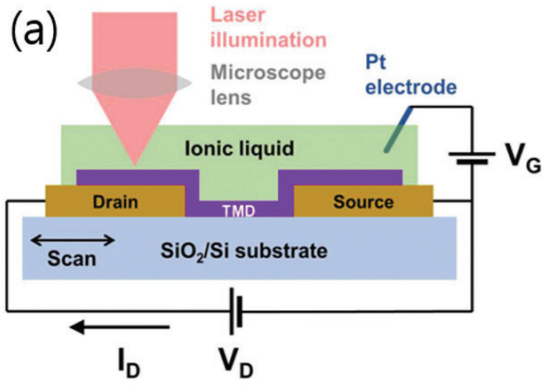

(b)

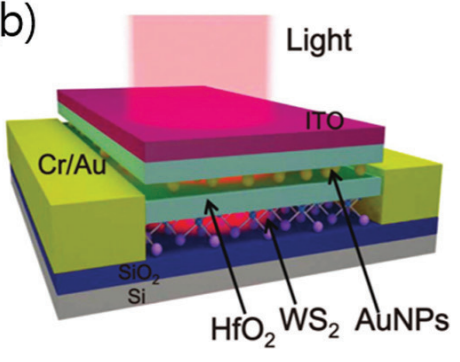

(e)

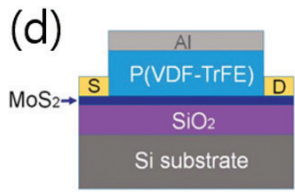

Fresh state

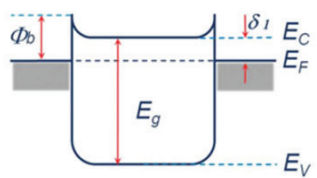

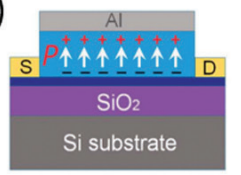

$\mathrm{P}$ up state (f)
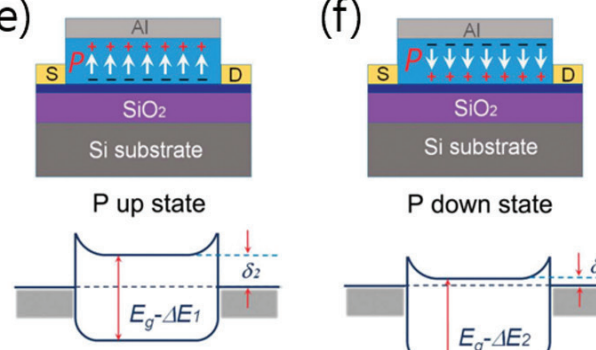

P down state

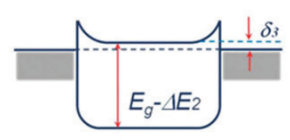

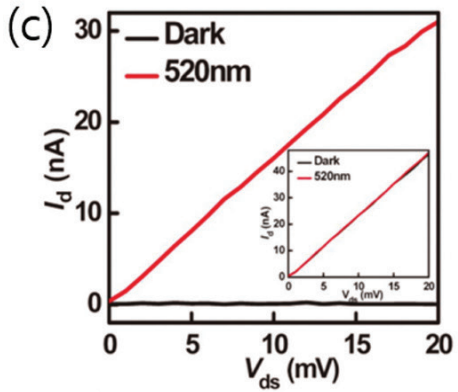

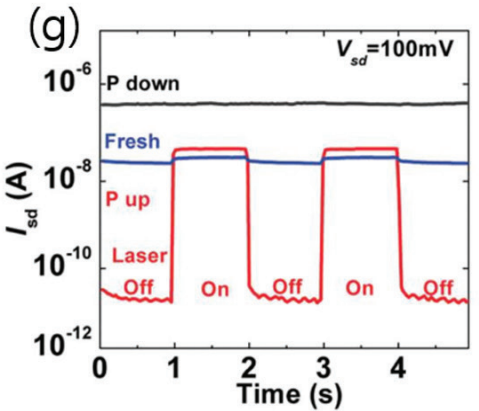

Fig. 13. (a) Schematic diagrams of 2D material based multimodal photodetector platform including both a vertical photodiode and a lateral phototransistor structure and experimental setup. ${ }^{71)}$ (b) 3D schematic view of the WS $\mathrm{S}_{2}$ phototransistor with gold nanoparticles (AuNPs) embedded in the gate dielectric. ${ }^{72)}$ (c) Output characteristics of the $\mathrm{WS}_{2}$ device with and without illumination in the program state. The inset shows similar measurements in the erase state. ${ }^{72)}(d-f)$ The cross-section structures of the device and equilibrium energy band diagrams of three different ferroelectric polarization states with $\bigvee_{\mathrm{sd}}=0 \mathrm{~V}$. For the band diagrams of different states, small Schottky barriers at the source and drain electrodes are considered. ${ }^{73)}(\mathrm{g})$ Photoswitching behavior of ferroelectric polarization gating triple layer $\mathrm{MoS}_{2}$ photodetector at three states $\left.\left(\lambda=635 \mathrm{~nm}, V_{\mathrm{sd}}=100 \mathrm{mV}, \mathrm{P}=100 \mathrm{nW}\right){ }^{73}\right)$

능을 비교한 연구결과가 보고되었다. ${ }^{62)}$ 그 결과 $\mathrm{h}-\mathrm{BN} /$ $\mathrm{FL}-\mathrm{ReS}_{2} / \mathrm{h}-\mathrm{BN}$ 디바이스에서 더욱 우수한 광 검출 성 능이 보였는데 이는 $\mathrm{ReS}_{2}$ 위에 적층한 $\mathrm{h}-\mathrm{BN}$ 이 추가적 인 보호 층으로 작용했기 때문이다.

연세대학교 연구팀은 유리기판 위에 다층의 $\mathrm{WSe}_{2}$ 와 $\mathrm{MoS}_{2}$ 를 증착하고 전극은 $\mathrm{ITO}$ 를 사용하여 투명한 태양전 지를 제작하였다(Fig. 12c). ${ }^{69)}$ 두께가 매우 얇은 $2 \mathrm{D}$ 소재 를 이용하기 때문에 80\%로 높은 투과도를 얻을 수 있 었으며 표면 흡착을 방지하기 위해 비정질 fluoropolymer Teflon AF2400를 스핀코팅 공정을 이용하여 얇게 증착 하였다. 그 결과 기존 대비 광전 변환 효율을 $10 \%$ 향상시 킬 수 있었다. 금속산화물을 소자 보호 층으로 사용한 연 구도 보고되었다. $\mathrm{MoS}_{2} / \mathrm{ZnPc}$ 헤테로 접합 포토트랜지 스터에 $30 \mathrm{~nm}$ 의 $\mathrm{Al}_{2} \mathrm{O}_{3}$ 층을 증착하여 소자 성능을 향상시 켰다. ${ }^{31)} \mathrm{MoS}_{2}$ 포토트랜지스터의 열화 및 습기를 방지하
기 위해 $\mathrm{ALD}$ 를 이용하여 초박형 $\mathrm{HfO}_{2}$ 보호 층을 증착 한 연구도 진행되었다(Fig. 12d). ${ }^{70)} \mathrm{HfO}_{2} / \mathrm{MoS}_{2}$ 소자는 외 부 환경에 의한 열화를 방지해 $\mathrm{MoS}_{2}$ 광 소자 대비 광 응 답성 및 응답속도를 크게 향상시킬 수 있었다. 위의 연구 결과들을 통해 확인된 것처럼 소자 보호 층의 도입은 외 부 흡착물이 $2 \mathrm{D}$ 채널 소재에 흡착되는 것을 막아줌으로 써 결국 빛에 의한 광분해를 지연시킬 수 있게 해주고 또 한 전하의 포획 현상도 상당히 줄일 수 있게 도와주어 궁 극적으로 광 소자의 신뢰성 및 안정성을 높여준다. 하지 만 보호 층으로 인해 발생하는 소자 특성의 급격한 변화 가 단순히 대기의 분자 흡착을 막아서 발생하는 것인지 아니면 의도하지 않은 채널 도핑의 결과인지를 밝혀내는 것 또한 중요할 것이다. 이를 위해 $2 \mathrm{D}$ 채널 소재와 보호 층의 종류에 따른 광 특성 변화에 대한 추가적인 연구가 필요할 것으로 사료된다. 


\section{6. 광 특성 향상 연구 (기타)}

일반적으로 수평 방향의 광전자 전도를 활용하는 포토 트랜지스터 구조는 높은 광학 이득을 얻는 장점이 있고 수직 포토다이오드 구조는 빠른 응답 및 저전력 작동이 가능한 장점이 있다. 이에 부응하여 미네소타대학교 연구 팀은 포토트랜지스터와 다이오드 각각의 장점을 활용하 기 위해 트랜지스터/다이오드 구조가 통합된 다기능의 광 검출기를 개발하였다. ${ }^{71)}$ 미리 제작된 소스/드레인 전 극에 다층 $\mathrm{MoS}_{2}$ 소재를 전사한 후 ionic liquid를 코팅 후 상부 전극을 최종 증착함으로써 광 센서 소자를 완성하였 다. 수평 방향의 $\mathrm{MoS}_{2}$ 채널은 포토트랜지스터의 채널로 이용하였으며 전극과 $\mathrm{MoS}_{2}$ 의 쇼트키 컨택면을 포토다이 오드로 이용하여 고속 응답은 물론 높은 광학 이득을 얻 을 수 있었다(Fig. 13a). 한편, $\mathrm{MoS}_{2}$ 또는 $\mathrm{WS}_{2}$ 는 채널, $\operatorname{AuNPs}\left(\mathrm{Au}\right.$ nanoparticles)는 플로팅 게이트, $\mathrm{HfO}_{2}$ 는 터널링 및 블로킹 유전체로 활용한 플로팅 게이트 형태의 포토트랜지스터 연구도 최근 진행되었다 (Fig. 13b). ${ }^{72)}$ 플로팅 게이트 AuNPs은 전자 포획을 유도함으로써 암전 류를 크게 낮추는 역할을 하고 $20 \mathrm{mV}$ 의 낮은 드레인 전 압 하에서 게이트 전압 인가 없이도 $1090 \mathrm{~A} / \mathrm{W}$ 의 큰 응 답성을 갖는 포토트랜지스터를 구현하였다 (Fig. 13c).

중국과학원 연구팀은 $\mathrm{P}(\mathrm{VDF}-\mathrm{TrFE})$ 강유전성 폴리머 필름을 게이트 유전체로 활용하여 $\mathrm{MoS}_{2}$ 포토트랜지스터 를 제작하였다. ${ }^{73)}$ 폴리머 필름의 강유전성에 의해 transfer 곡선의 히스테리시스(hysteresis)가 크게 관찰 되었으며 게이트 전압의 인가를 없애도 분극이 남아있었 다. 분극이 없을 때와 분극의 방향이 채널 쪽(P down state)을 향할 때와 비교했을 때 분극이 게이트 전극 쪽 (P up state)을 향할 때 광 응답성이 현저하게 상승하였 으며, zero 게이트 전압에서도 검출기의 감도가 우수하 게 유지되었다. 이러한 특수한 성질을 바탕으로, 2570 $\mathrm{A} / \mathrm{W}$ 의 높은 응답성을 가진 광 검출기를 개발하였으며 광 응답 파장 영역이 가시광선으로부터 근적외선(0.85$55 \mathrm{~m}$ )까지 더 확장된 것을 보여주었다(Fig. $13 \mathrm{~d}-\mathrm{g}$ ). 또 한 같은 강유전성 폴리머를 $\mathrm{In}_{2} \mathrm{Se}_{3}$ flake에도 적용하여

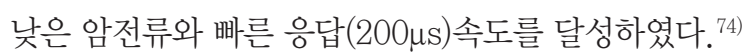

\section{7. 결론}

$2 \mathrm{D}$ 소재는 높은 광 흡수 계수 및 높은 전하 이동 특성 때문에 고성능 광 센서에 대한 큰 가능성을 보여주었다. 본 리뷰논문에서는 $2 \mathrm{D}$ 소재를 기반으로 하는 광 검출 소 자에서 중요한 구성 요소 기술들(채널, 컨택, 계면, 보호 층)과 관련된 연구 결과들을 살펴보았고 광 센서 소자의 성능을 정량적으로 평가하기 위한 다양한 성능 지수(응답 성, 검출도, 반응속도, 검출 파장 범위 등)를 비교 검토하 였다.

광 센서의 채널 층은 단일물질보다는 주로 하이브리드 의 헤테로 구조를 형성하는 방향으로 연구가 진행되고 있 는 추세이다. $2 \mathrm{D}$ 소재의 반데르발스 결합은 다양한 차원 의 광 소자 플랫폼 $(2 \mathrm{D}-0 \mathrm{D}, 2 \mathrm{D}-1 \mathrm{D}, 2 \mathrm{D}-2 \mathrm{D}, 2 \mathrm{D}-3 \mathrm{D}$ 등)을 가능하게 하였고 이런 헤테로 구조의 광 센서 소자 는 전반적으로 광 흡수 효율을 증가시킬 뿐만 아니라 검 출 파장 스펙트럼 범위를 넓히는 효과가 있었다. 전극과 $2 \mathrm{D}$ 소재의 접촉 물성은 광 검출기의 검출 성능에 상당히 영향을 미치는 중요한 요소 중 하나이다. 금속/2D 재료 의 접촉면에 형성되는 쇼트키 장벽은 전하 이동을 어렵게 해 소자 성능의 저하를 초래한다. 따라서 접촉 계면에 금 속산화물 또는 $2 \mathrm{D}$ 절연체 소재를 삽입한 연구가 보고되 었다. 계면에 대한 연구로는 $2 \mathrm{D}$ 물질과 기판과의 계면, $2 \mathrm{D}$ 물질과 헤테로 접합한 다른 차원의 소재에서 발생하 는 결함을 최소화하는 연구가 주로 진행되었다. $2 \mathrm{D}$ 광 센 서 소자 보호 층은 대기중의 습기와 공기 분자에 대한 노 출을 억제시켜 광분해 열화 현상을 막는 중요한 기술로 부상하고 있다.

기존 상용화된 광 검출기를 대체할 정도로 적합한 $2 \mathrm{D}$ 기반의 광 검출기를 구현하기 위해서는 여전히 상당한 연 구가 필요한 실정이다. 특히 광 검출 성능 지수(응답성, 검출도, 반응속도, $\mathrm{EQE}$, 파장 스펙트럼 범위 등)를 향상 시키는 연구뿐만 아니라 2D 소재 물질 자체에 대한 고품 위의 대면적 성장 및 집적화 어레이 공정 기술이 필수적 이다. 뿐만 아니라 장기 안정성 및 신뢰성을 확인하기 위 한 테스트가 필수적이다. $2 \mathrm{D}$ 물질이 광 센서 소자 분야에 서 상당한 장점을 갖고 있음에도 불구하고 여전히 재료 
합성 연구, 소자 구조 설계 기술 고도화, 집적화 공정 기 술, 양자 기반 시뮬레이션 예측 기술 등이 융합될 때 $2 \mathrm{D}$ 광 검출기의 비약적인 발전이 가능할 것으로 보인다.

\section{8. 감사의 글}

이 성과는 2018년도 정부(과학기술정보통신부)의 재원 으로 한국연구재단의 지원을 받아 수행된 연구임(No. 2017R1C1B1005076)

\section{참고문헌}

1. Yao, J. D., Zheng, Z. Q., Shao, J. M. \& Yang, G. W. "Stable, highly-responsive and broadband photodetection based on large-area multilayered $\mathrm{WS}_{2}$ films grown by pulsed-laser deposition". Nanoscale 7, 14974-14981 (2015).

2. Octon, T. J., Nagareddy, V. K., Russo, S., Craciun, M. F. \& Wright, C. D. "Fast High-Responsivity FewLayer $\mathrm{MoTe}_{2}$ Photodetectors". Adv. Optical Mater. 4, 1750 - 1754 (2016).

3. Yim, C. et al. "High-Performance Hybrid Electronic Devices from Layered $\mathrm{PtSe}_{2}$ Films Grown at Low Temperature". ACS Nano 10, 9550-9558 (2016).

4. Jiao, L., Jie, W., Yang, Z., Wang, Y. \& Chen, Z. "Layer-dependent photoresponse of $2 \mathrm{D} \mathrm{MoS}_{2}$ films prepared by pulsed laser deposition". J. Mater. Chem. C7, 2522-2529 (2019).

5. Huang, M. et al. "Broadband Black-Phosphorus Photodetectors with High Responsivity". Adv. Mater. 28, 3481-3485 (2016).

6. Miao, J. et al. "Single Pixel Black Phosphorus Photodetector for Near-Infrared Imaging". Small 14, 1702082-1702088 (2018).

7. Jia, Z. et al. "Enhanced Photoresponse of $\mathrm{SnSe}^{-}$ Nanocrystals-Decorated $\mathrm{WS}_{2} \quad$ Monolayer Phototransistor". ACS Appl. Mater. Interfaces 8, 4781-4788 (2016).

8. Qiao, S. et al. "A vertically layered $\mathrm{MoS}_{2} / \mathrm{Si}$ heterojunction for an ultrahigh and ultrafast photoresponse photodetector". J. Mater. Chem. C6, 3233 - 3239 (2018).

9. Kim, H., Patel, M., Kim, J. \& Jeong, M. S. "Growth of Wafer-Scale Standing Layers of $\mathrm{WS}_{2}$ for SelfBiased High-Speed UV-Visible-NIR Optoelectronic
Devices”. ACS Appl. Mater. Interfaces 10, 3964-3974 (2018).

10. Sun, M. et al. "Heterostructured graphene quantum dot / $\mathrm{WSe}_{2} / \mathrm{Si}$ photodetector with suppressed dark current and improved detectivity". Nano Research 11 (6), 3233-3243 (2018).

11. Nguyen, D. A. et al. "Highly Enhanced Photoresponsivity of a Monolayer $\mathrm{WSe}_{2}$ Photodetector with Nitrogen-Doped Graphene Quantum Dots". ACS Appl. Mater. Interfaces 10, 10322-10329 (2018).

12. Yu, Y. et al. "PbS-Decorated $\mathrm{WS}_{2}$ Phototransistors with Fast Response". ACS Photonics 4, 950-956 (2017).

13. Hu, C. et al. "Synergistic Effect of Hybrid PbS Quantum Dots / 2D-WSe 2 Toward High Performance and Broadband Phototransistors". Adv. Funct. Mater. 27, 1603605-1603612 (2017).

14. Wu, H. et al. "All-Inorganic Perovskite Quantum Dot-Monolayer $\mathrm{MoS}_{2}$ Mixed-Dimensional van der Waals Heterostructure for Ultrasensitive Photodetector." Adv. Sci. 5, 1801219-1801227, (2018).

15. Bera, S., Gupta, D., Ray, S. K. \& Sapra, S. "MoSe $-\mathrm{Cu}_{2} \mathrm{~S}$ Vertical $\mathrm{p}-\mathrm{n}$ Nanoheterostructures for HighPerformance Photodetectors". ACS Appl. Mater. Interfaces 11, 4074-4083, (2019)

16. Guo, N. et al. "Hybrid $\mathrm{WSe}_{2}-\mathrm{In}_{2} \mathrm{O}_{3}$ Phototransistor with Ultrahigh Detectivity by Efficient Suppression of Dark Currents". ACS Appl. Mater. Interfaces 9, 34489-34496 (2017).

17. Henning, A, et al. "Charge Separation at MixedDimensional Single and Multilayer $\mathrm{MoS}_{2} /$ Silicon Nanowire Heterojunctions". ACS Appl. Mater. Interfaces 10, 16760 - 16767 (2018).

18. Kim, S. J. et al. "Fabrication of high-performance flexible photodetectors based on $\mathrm{Zn}$-doped $\mathrm{MoS}_{2} /$ graphene hybrid fibers". J. Mater. Chem. C5, 1235412359 (2017).

19. Ye, L., Li, H., Chen, Z. \& Xu, J. "Near-Infrared Photodetector Based on $\mathrm{MoS}_{2} /$ Black Phosphorus Heterojunction”. ACS Photonics 3, 692-699 (2016).

20. Long, M. et al. "Broadband Photovoltaic Detectors Based on an Atomically Thin Heterostructure". Nano Lett. 16 (4), 2254- 2259 (2016).

21. Chen, Z. A. "high performance self-driven photodetector based on a graphene/InSe/ $\mathrm{MoS}_{2}$ vertical heterostructure". J. Mater. Chem. C6, 12407-124122 (2018). 
22. Jeong, H. et al. "Metal-Insulator-Semiconductor Diode Consisting of Two-Dimensional Nanomaterials". Nano Lett. 16, 1858-1862 (2016).

23. Tan, H. et al. "Ultrathin 2D Photodetectors Utilizing Chemical Vapor Deposition Grown $\mathrm{WS}_{2}$ With Graphene Electrodes". ACS Nano 10 (8), 7866-7873 (2016).

24. Tan, H. et al. "Lateral Graphene-Contacted Vertically Stacked $\mathrm{WS}_{2}$ / $\mathrm{MoS}_{2}$ Hybrid Photodetectors with Large Gain". Adv. Mater. 29, 1702917-1702924 (2017).

25. Zheng, W. et al. "Anisotropic Growth of Nonlayered $\mathrm{CdS}$ on $\mathrm{MoS}_{2}$ Monolayer for Functional Vertical Heterostructures". Adv. Funct. Mater. 16, 2648-2654 (2016).

26. Yang, T. et al. "Van der Waals epitaxial growth and optoelectronics of large-scale $\mathrm{WSe}_{2} / \mathrm{SnS}_{2}$ vertical bilayer $\mathrm{p}-\mathrm{n}$ junctions". Nat. Commun. 8, 1906-1914 (2017).

27. Xue, Y. et al. "Scalable Production of a Few-Layer $\mathrm{MoS}_{2} / \mathrm{WS}_{2}$ Vertical Heterojunction Array and Its Application for Photodetectors". ACS Nano 10, 573580 (2016).

28. Chen, C. et al. "Large-Scale Synthesis of a Uniform Film of Bilayer $\mathrm{MoS}_{2}$ on Graphene for 2D Heterostructure Phototransistors". ACS Appl. Mater. Interfaces 8 (29), 19004-19011 (2016).

29. Wang, F. et al. "Tunable GaTe-MoS van der Waals $\mathrm{p}-\mathrm{n}$ Junctions with Novel Optoelectronic Performance". Nano Lett. 15, 7558-7566 (2015).

30. Yang, S. et al. "Self-Driven Photodetector and Ambipolar Transistor in Atomically Thin GaTe--MoS $\mathrm{p}-\mathrm{n}$ vdW Heterostructure". ACS Appl. Mater. Interfaces 8 (4), 2533 - 2539 (2016).

31. Huang, Y. et al. "Van der Waals Coupled Organic Molecules with Monolayer $\mathrm{MoS}_{2}$ for Fast Response Photodetectors with Gate-Tunable Responsivity". ACS Nano 12, 4062-4073 (2018).

32. Xu, H. et al. "High Detectivity and Transparent FewLayer $\mathrm{MoS}_{2} /$ Glassy-Graphene Heterostructure Photodetector". Adv. Mater. 30 (13), 17065611706569, (2018).

33. Zhang, K. et al. "Interlayer Transition and Infrared Photodetection in Atomically Thin Type-II $\mathrm{MoTe}_{2}$ / $\mathrm{MoS}_{2}$ van der Waals Heterostructures". ACS Nano 10, 3852-3858 (2016).

34. Li, B. et al. "3D Band Diagram and Photoexcitation of 2D - 3D Semiconductor Heterojunctions". Nano Lett.
15, 5919-5925 (2015).

35. Kim, Y. et al. "Facile Fabrication of a TwoDimensional TMD/Si Heterojunction Photodiode by Atmospheric-Pressure Plasma-Enhanced Chemical Vapor Deposition”. ACS Appl. Mater. Interfaces 10, 36136 - 36143 (2018).

36. Hwang, I., Kim, J. S., Cho, S. H., Jeong, B. \& Park, C. "Flexible Vertical $\mathrm{p}-\mathrm{n}$ Diode Photodetectors with Thin N-type $\mathrm{MoSe}_{2}$ Films Solution-Processed on Water Surfaces". ACS Appl. Mater. Interfaces 10, 34543 - 34552 (2018).

37. Geng, X. et al. "Design and construction of ultra-thin $\mathrm{MoSe}_{2}$ nanosheet- based heterojunction for highspeed and low-noise photodetection". Nano Research 9, $2641-2651$ (2016).

38. Kim, H. -S. et al. "High-performing $\mathrm{MoS}_{2}$-embedded Si photodetector". Materials Science in Semiconductor Processing 71, 35 - 41 (2017).

39. Lan, C. et al. "Zener Tunneling and Photoresponse of a $\mathrm{WS}_{2}$ /Si van der Waals Heterojunction”. ACS Appl. Mater. Interfaces 8, 18375-18382 (2016).

40. Yim, C. et al. "Wide Spectral Photoresponse of Layered Platinum Diselenide-Based Photodiodes". Nano Lett. 18, 1794-1800 (2018).

41. Zheng, Z. et al. "Fabrication of a high performance $\mathrm{ZnIn}_{2} \mathrm{~S}_{4} / \mathrm{Si}$ heterostructure photodetector array for weak signal detection”. J. Mater. Chem. C6, 1292812939 (2018)

42. Yang, J. et al. "MoS ${ }_{2}$ - InGaZnO Heterojunction Phototransistors with Broad Spectral Responsivity". ACS Appl. Mater. Interfaces 8, 8576-8582 (2016).

43. Pak, S. W., Chu, D., Song, D. Y., Lee, S. K. \& Kim, E. K. "Enhancement of near-infrared detectability from $\mathrm{InGaZnO}$ thin film transistor with $\mathrm{MoS}_{2}$ light absorbing layer". Nanotechnology 28, 475206 (2017).

44. $\mathrm{Ma}, \mathrm{C}$. et al. "Heterostructured $\mathrm{WS}_{2} / \mathrm{CH}_{3} \mathrm{NH}_{3} \mathrm{PbI}_{3}$ Photoconductors with Suppressed Dark Current and Enhanced Photodetectivity". Adv. Mater. 28 (19) 3683 - 3689 (2016).

45. Jo, S. et al. "A High-Performance $\mathrm{WSe}_{2} / \mathrm{h}-\mathrm{BN}$ Photodetector using a Triphenylphosphine $\left(\mathrm{PPh}_{3}\right)$ -Based n-Doping Technique" Adv. Mater. 28, 4824 4831 (2016)

46. Xiang, D. et al. "Surface transfer doping induced effective modulation on ambipolar characteristics of few-layerblack phosphorus". Nature Communications 6, 6485 (2015).

47. Kang, D. et al. "High-Performance Transition Metal 
Dichalcogenide Photodetectors Enhanced by SelfAssembled Monolayer Doping". Adv. Funct. Mater. 25, 4219 - 4227 (2015).

48. Kang, D. et al. "Self-Assembled Layer (SAL)-Based Doping on Black Phosphorus (BP) Transistor and Photodetector". ACS Photonics 4, 1822-1830 (2017).

49. Lu, J. et al. "Hybrid Bilayer $\mathrm{WSe}_{2}-\mathrm{CH}_{3} \mathrm{NH}_{3} \mathrm{PbI}_{3}$ Organolead Halide Perovskite as a High-Performance Photodetector". Angew. Chem. 128, 12124-12128 (2016).

50. Lee, K. H., Kim, T., Shin, H. \& Kim, S. "Highly Efficient Photocurrent Generation from Nano crystalline Graphene - Molybdenum Disulfide Lateral Interfaces". Adv. Mater. 28, 1793-1798 (2016).

51. Wu, W. et al. "Self-Powered Photovoltaic Photodetector Established on Lateral Monolayer $\mathrm{MoS}_{2}-\mathrm{WS}_{2}$ Heterostructures". Nano Energy 51, 45-53 (2018).

52. Yao, J. \& Yang, G. "Flexible and High-Performance All-2D Photodetector for Wearable Devices". Small 14, 1704524-1704531 (2018).

53. Pak, Y., Park, W., Mitra, S., Devi, A. A. S., Loganathan, K., Kumaresan, Y., Kim, Y., Cho, B., Jung, G.-Y., Hussain, M. M., \& Rogan, I. S. "Enhanced Performance of $\mathrm{MoS}_{2}$ Photodetectors by Inserting an $\mathrm{ALD}-$ Processed $\mathrm{TiO}_{2}$ Interlayer". Small 14, 1703176-1703181 (2018).

54. Mandrus, D., Zhou, Z. \& Xu, Y. "High-Performance $\mathrm{WSe}_{2}$ Phototransistors with 2D/2D Ohmic Contacts". Nano Lett. 18, 2766 - 2771 (2018).

55. Liu, J. et al. "Pronounced Photovoltaic Response from Multi-layered $\mathrm{MoTe}_{2}$ Phototransistor with Asymmetric Contact Form". Nanoscale Research Letters 12, 603-610 (2017).

56. Zhou, C. et al. "Self-Driven Metal-Semiconductor - Metal WSe $\mathrm{S}_{2}$ Photodetector with Asymmetric Contact Geometries". Adv. Funct. Mater. 28, 18029541802961 (2018).

57. Chen, J., Jang, C., Xiao, S., Ishigami, M. \& Fuhrer, M. S. "Intrinsic and extrinsic performance limits of graphene devices on $\mathrm{SiO}_{2}$. . Nature Nanotechnology 3, 206-209 (2008).

58. Phys, A. "MoS 2 nanosheet photodetectors with ultrafast response". Appl. Phys. Lett. 111, 153502 (2017).

59. Britnell, L. et al. "Electron Tunneling through Ultrathin Boron Nitride Crystalline Barriers". Nano
Lett. 12, 1707-1710 (2012).

60. Britnell, L. et al. "Field-Effect Tunneling Transistor Based on Vertical Graphene Heterostructures". Science 335, 947-950 (2012).

61. Samassekou, H. et al. "Viable route towards largearea $2 \mathrm{D} \mathrm{MoS}_{2}$ using magnetron sputtering”. 2D Mater. 4, 021002 (2017).

62. Nazir, G. et al. "Comparison of Electrical and Photoelectrical Properties of $\mathrm{ReS}_{2}$ Field-Effect Transistors on Different Dielectric Substrates". ACS Appl. Mater. Interfaces 10, 32501-32509 (2018).

63. Zhu, Y. et al. "High-Efficiency Monolayer Molybdenum Ditelluride Light-Emitting Diode and Photodetector". ACS Appl. Mater. Interfaces 10, 43291 - 43298 (2018).

64. Huo, N., Gupta, S. \& Konstantatos, G. "MoS $-\mathrm{HgTe}$ Quantum Dot Hybrid Photodetectors beyond $2 \mu \mathrm{m} \gg$. Adv. Mater. 29, 1606576-1606580 (2017).

65. Liu, Q. et al. "Printable Transfer-Free and WaferSize $\mathrm{MoS}_{2} /$ Graphene van der Waals Heterostructures for High-Performance Photodetection”. ACS Appl. Mater. Interfaces 9, 12728-12733 (2017).

66. Parzinger, E., et al. "Photocatalytic Stability of Single-and Few-Layer MoS?”. ACS Nano 9 (11), $11302-11309$ (2015).

67. Yamamoto, M., Dutta, S., Aikawa, S., Nakaharai, S. \& Wakabayashi, K. "Self-Limiting Layer-by-Layer Oxidation of Atomically Thin WSe". Nano Lett. 15, 2067-2073 (2015).

68. Ahn, S. et al. "Prevention of Transition Metal Dichalcogenide Photodegradation by Encapsulation with h-BN Layers". ACS Nano 10 (9), 8973-8979 (2016).

69. Cho, A., Song, M., Kang, D. \& Kwon, J. "TwoDimensional $\mathrm{WSe}_{2} / \mathrm{MoS}_{2} \mathrm{p}-\mathrm{n}$ Heterojunction-Based Transparent Photovoltaic Cell and Its Performance Enhancement by Fluoropolymer Passivation". ACS Appl. Mater. Interfaces 10, 35972 - 35977 (2018).

70. Kufer, D. \& Konstantatos, G. "Highly Sensitive, Encapsulated $\mathrm{MoS}_{2}$ Photodetector with Gate Controllable Gain and Speed”. Nano Lett. 15, 73077313 (2015).

71. Namgung, S., Shaver, J., Oh, S. \& Koester, S. J. "Multimodal Photodiode and Phototransistor Device Based on Two-Dimensional Materials". ACS Nano 10 (11), 10500 - 10506 (2016).

72. Gong, F. et al. "High-Sensitivity Floating-Gate Phototransistors Based on $\mathrm{WS}_{2}$ and $\mathrm{MoS}_{2}{ }^{\prime}$. $A d v$. 
Funct. Mater. 26, 6084 -6090 (2016).

73. Wang, X. et al. "Ultrasensitive and Broadband $\mathrm{MoS}_{2}$ Photodetector Driven by Ferroelectrics". Adv. Mater. 27, 6575-6581 (2015).

74. Wu, G., Wang, X., Wang, P., Huang, H. \& Chen, Y.
"Visible to short wavelength infrared $\mathrm{In}_{2} \mathrm{Se}_{3}-$ nanoflake photodetector gated by a ferroelectric polymer." Nanotechnology 27, 364002-364008 (2016).
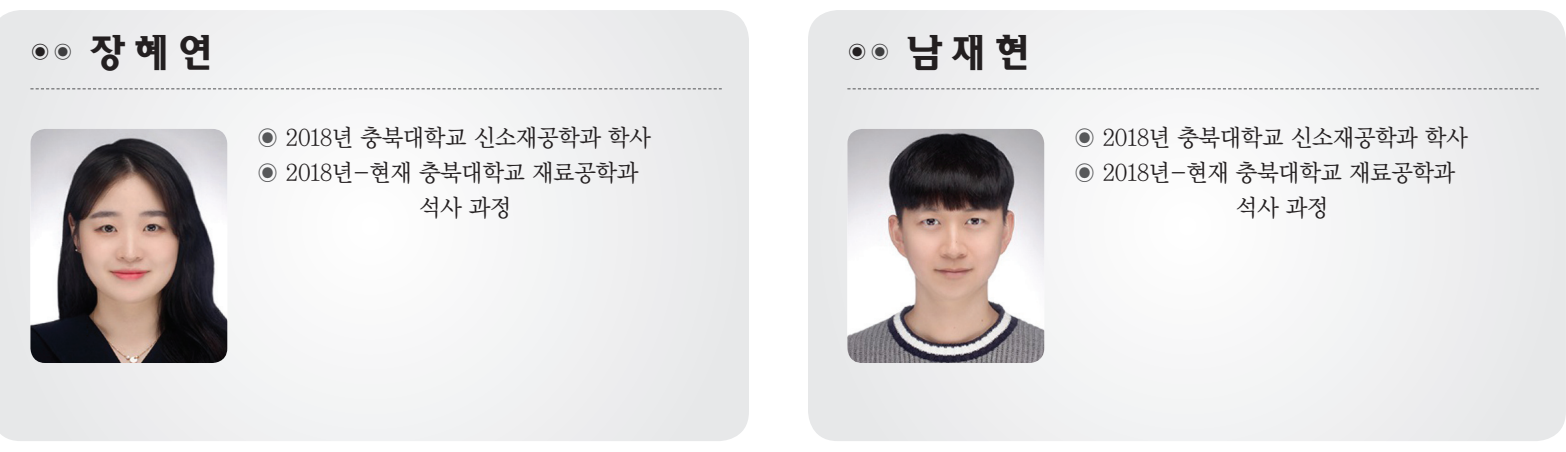

\section{○○ 조병 진}

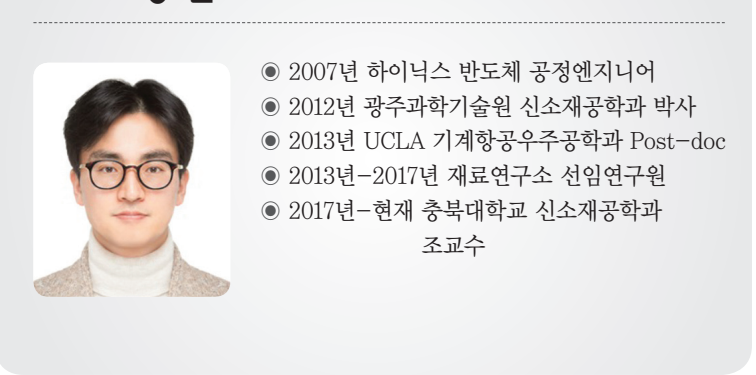

